ARTICLE

https://doi.org/10.1038/s41467-018-08111-y

\title{
The CHD6 chromatin remodeler is an oxidative DNA damage response factor
}

\author{
Shaun Moore ${ }^{1}$, N. Daniel Berger ${ }^{1}$, Martijn S. Luijsterburg ${ }^{2}$, Cortt G. Piett ${ }^{3}$, Fintan K.T. Stanley ${ }^{1}$, \\ Christoph U. Schräder ${ }^{1}$, Shujuan Fang ${ }^{1}$, Jennifer A. Chan ${ }^{1}$, David C. Schriemer ${ }^{1}$, Zachary D. Nagel ${ }^{3}$, \\ Haico van Attikum ${ }^{2} \&$ Aaron A. Goodarzi ${ }^{1}$
}

Cell survival after oxidative DNA damage requires signaling, repair and transcriptional events often enabled by nucleosome displacement, exchange or removal by chromatin remodeling enzymes. Here, we show that Chromodomain Helicase DNA-binding protein 6 (CHD6), distinct to other CHD enzymes, is stabilized during oxidative stress via reduced degradation. CHD6 relocates rapidly to DNA damage in a manner dependent upon oxidative lesions and a conserved $\mathrm{N}$-terminal poly(ADP-ribose)-dependent recruitment motif, with later retention requiring the double chromodomain and central core. CHD6 ablation increases reactive oxygen species persistence and impairs anti-oxidant transcriptional responses, leading to elevated DNA breakage and poly(ADP-ribose) induction that cannot be rescued by catalytic or double chromodomain mutants. Despite no overt epigenetic or DNA repair abnormalities, CHD6 loss leads to impaired cell survival after chronic oxidative stress, abnormal chromatin relaxation, amplified DNA damage signaling and checkpoint hypersensitivity. We suggest that CHD6 is a key regulator of the oxidative DNA damage response.

\footnotetext{
${ }^{1}$ Robson DNA Science Centre, Arnie Charbonneau Cancer Institute, Departments of Biochemistry \& Molecular Biology and/or Oncology, Cumming School of Medicine, University of Calgary, Calgary, AB T2N 4N1, Canada. ${ }^{2}$ Department of Human Genetics, Leiden University Medical Center, Einthovenweg 20,2333 ZC Leiden, The Netherlands. ${ }^{3}$ Harvard University, School of Public Health, Boston, MA 02115, USA. These authors contributed equally: N. Daniel Berger, Martijn S. Luijsterburg, Cortt G. Piett, Fintan K. T. Stanley. Correspondence and requests for materials should be addressed to

A.A.G. (email: A.Goodarzi@ucalgary.ca)
} 
E ukaryotic DNA is packaged with histones to form nucleosomes, the functional unit of chromatin. Chromatin remodeling enzymes adjust nucleosome spacing to regulate DNA accessibility and transcription in response to stimuli, and are essential components of DNA damage responses that are altered often in cancer ${ }^{1}$. The nine-member family of chromodomainhelicase-DNA binding (CHD) chromatin remodeling enzymes is characterized by the double chromodomain and a central ATPase-helicase domain that confers nucleosome respacing, removal or exchange activity ${ }^{2}$. Among the CHD enzymes, CHD1, CHD2, CHD3.1 and CHD4 have roles in DNA damage repair pathways $^{3-13}$. No definitive roles for CHD5-9 within the DNA damage response have been described to date, although both CHD5 and CHD6 expression are known to be altered in cancer ${ }^{1}$. CHD6 was actually the fifth CHD protein discovered and, after initially being called $\mathrm{CHD}^{14}$, its name was changed to $\mathrm{CHD} 6$ when another protein (now called CHD5) was identified with greater homology to $\mathrm{CHD} 3$ and $\mathrm{CHD} 4^{15}$.

CHD chromatin remodelers generally adjust linker DNA length between nucleosomes, increasing per capita histone occupancy and disfavoring sequence-positioned nucleosome deposition $^{16}$. Purified CHD6 disrupts and re-positions nucleosomes, albeit in a non-sliding manner distinct to $\mathrm{CHD} / 8^{17}$. CHD6 is expressed ubiquitously in mammalian tissue, although little is known about its molecular function. $\mathrm{H} 3^{\mathrm{K} 4 \mathrm{me} 3}$-independent promoter occupancy in mouse embryonic stem cells indicates that CHD6 is present at both sites of active and inactive transcription ${ }^{18}$. The impact of CHD6 enzymatic activity in vivo, as well as what genomic regions are regulated by CHD6 in a human and/or differentiated cell, are still unclear. Catalytic inactivation deletion of exon 12 (encoding a conserved portion of ATPase domain) in mice causes cerebellar defects and ataxia ${ }^{19}$. Morphological analysis revealed no structural cerebellar defects in CHD6 $\Delta$ exon12 mice, suggesting that CHD6 is not dominant in development, but prevents progressive cerebellar degeneration, which is a frequently documented consequence of failure to suppress or resolve DNA damage leading to neuronal death within the central nervous system ${ }^{20,21}$. CHD6 is a known cancer driver $^{22}$ and, according to The Cancer Genome Atlas, is overexpressed in cancers arising in oxidatively stressed tissue microenvironments, including colorectal, uterine, gastric, lung and pancreatic cancers ${ }^{23,24}$. In A549 human lung carcinoma cells, CHD6 messenger RNA (mRNA) has been reported to increase slightly with very low (but not high) ionizing radiation (IR) doses $^{25}$, although the significance of this is unclear.

Here, we present evidence that CHD6 stabilizes during oxidative stress, relocates dynamically to sites of oxidative DNA damage and is a key component of the signaling and transcriptional response to reactive oxygen species (ROS) exposure. We define a mechanism by which cell survival in oxidatively stressed human cells is driven by the chromatin remodeler CHD6.

\section{Results}

CHD6 levels fluctuate and stabilize during oxidative stress. We first analyzed CHD6 protein levels in cells under various oxidative stress conditions, as previous work had only examined CHD6 mRNA by northern blot after IR $^{25}$. Whole cell extracts of A549 cells grown to confluence in either $3 \%$ or ambient $(21 \%) \mathrm{O}_{2}$ were immunoblotted for CHD6, p53 (as a control for DNA damage response activation) and actin (Fig. 1a). CHD6 was weakly detectable in cells grown in $3 \% \mathrm{O}_{2}$, but increased substantially in $21 \% \mathrm{O}_{2}$. CHD6 protein levels responded dynamically to $\mathrm{O}_{2}$, and dropped within several hours of cells being transferred from 21 to $3 \% \mathrm{O}_{2}$. We also examined whether CHD1, CHD2, CHD3.1 or $\mathrm{CHD} 4$, the CHD enzymes previously described to have a role in the DNA damage response, displayed dynamic alteration in expression under the same conditions (Fig. 1b, c). In all cases, no significant increase in protein expression was observed, highlighting a unique mode of regulation for CHD6 among these enzymes. In contrast to previous reports ${ }^{25}$, quantitative PCR (qPCR) revealed no significant increase in CHD6 mRNA over a $24 \mathrm{~h}$ period following oxidative stress (Fig. 1d). While etoposide treatment, a source of non-oxidative DNA damage, did not alter CHD6 expression (Fig. 1e), acute $\mathrm{H}_{2} \mathrm{O}_{2} / \mathrm{IR}$ exposure triggered an increase in total CHD6 protein, indicating a selective response to multiple sources of oxidative stress (Fig. If, g). We speculated that the rapid $(<30 \mathrm{~min})$ change in CHD6 protein level was likely via reduced proteasome degradation. Fitting with this hypothesis, bortezomib, which blocks proteasome-mediated degradation, stabilized CHD6 levels to those observed after $\mathrm{H}_{2} \mathrm{O}_{2} / \mathrm{IR}$ (Fig. 1f, g).

CHD6 is recruited dynamically to oxidative DNA damage. We next asked whether, in addition to protein level stabilization, oxidative DNA damage alters CHD6 intracellular localization. We cloned human CHD6 complementary DNA (cDNA) into Nterminally green fluorescent protein (GFP)- or C-terminally FLAG-tag expression constructs (controlling for type of epitope and position) and transfected these into A549 cells. CHD6 ${ }^{\mathrm{GFP}}$ and $\mathrm{CHD6}^{\mathrm{FLAG}}$ expressed well, did not impact short-term cell viability adversely and were exclusively nuclear (Fig. 1h); moreover, we were also able to detect endogenous CHD6 (Fig. 1h). Bromodeoxyuridine (BrdU)-treated cells were subjected to 355 $\mathrm{nm}$ laser micro-irradiation, harvested $5 \mathrm{~min}$ later and immunostained for DNA damage response markers. Endogenous CHD6, CHD6 $^{\mathrm{GFP}}$ and CHD6 ${ }^{\mathrm{FLAG}}$ localized to micro-irradiation tracks overlapping with $\gamma \mathrm{H} 2 \mathrm{AX}$ and/or poly(ADP-ribose) (PAR) (Fig. 1h). Our micro-irradiation power was equivalent to $\sim 8 \mathrm{~Gy}$ IR (Supplementary Fig. 1a). CHD6 GFP relocalizes to sites of DNA damage in a multi-phasic fashion, involving very fast $(\sim 1 \mathrm{~min})$ recruitment, slower accumulation between 1 and 8 min, relatively stable retention from 8 to $16 \mathrm{~min}$ and then a steady decline. This is in contrast to XRCC1 ${ }^{\text {GFP }}$ and PARP1 ${ }^{\text {GFP }}$ that, under identical conditions, display only rapid recruitment and immediate dispersal (Fig. 1i). Laser micro-irradiation produces many oxidative DNA lesions, including oxidized bases, single-strand breaks (SSBs) and double-strand breaks (DSBs). To better distinguish the general class of DNA damage that attracts CHD6, we used a sitespecific system ${ }^{26}$ whereby DNA damage is produced at a single genomic locus (a LacO array) by either LacR-fused Fok1 nuclease (DSBs, non-oxidative damage) or LacR-fused KillerRed (ROSmediated damage) (Fig. 2a). CHD6 ${ }^{\mathrm{GFP}}$ was not recruited to Fok1 nuclease-induced DNA damage, despite $\gamma \mathrm{H} 2 \mathrm{AX}$ formation and XRCC4 retention at the Fok $1^{\text {LacR }}$-bound array, indicative of DSB formation and active repair complex formation (Fig. 2b, d). In contrast, $\mathrm{CHD} 6 \mathrm{GFP}$ accumulated robustly at sites of ROS-induced DNA damage mediated by light-stimulated KillerRed ${ }^{\text {LacR }}$ (Fig. 2c, d). KillerRed-induced DNA damage sites were demarcated by XRCC1 (a key base excision and SSB repair factor), PAR, XRCC4 and weak $\gamma \mathrm{H} 2 \mathrm{AX}$ (Fig. 2c-e). KillerRed-mediated DNA damage induction was comparable to $1 \mathrm{mM} \mathrm{H}_{2} \mathrm{O}_{2}$ treatment in media (Fig. 2f-h). These data suggest that ROS-induced DNA lesions, but not enzymatic (non-oxidative) DNA damage types, are required to elicit CHD6 recruitment, similar to our earlier observations with CHD6 expression.

CHD6 recruitment to DNA damage is PAR dependent. To address how CHD6 is recruited to DNA damage, we used microirradiation, which permits real-time spatiotemporal kinetic analysis of CHD6 relocalization. CHD6 accumulation at DNA 
a
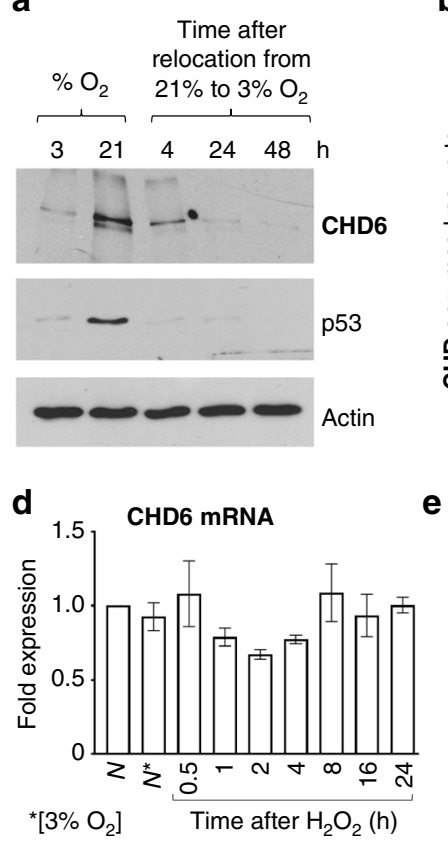

f

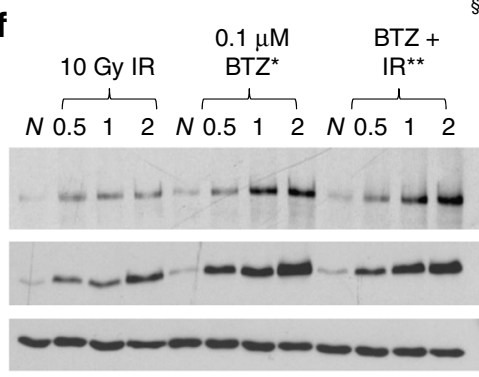

g

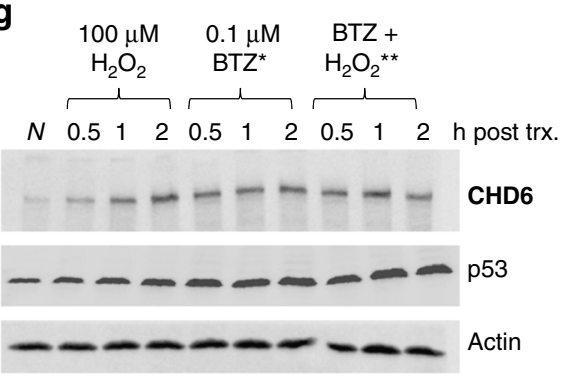

${ }^{\star} B T Z$ (bortezomib) added 90 min prior to $t=0$

${ }^{\star *} \mathrm{BTZ}$ added 90 min prior to $\mathrm{H}_{2} \mathrm{O}_{2}$ or $I R$ at $t=0$ b

$3 \% 21 \% \rightarrow 3 \% \mathrm{O}_{2}$

$\mathrm{O}_{2}$ Oh $4 \mathrm{~h} 24 \mathrm{~h}$
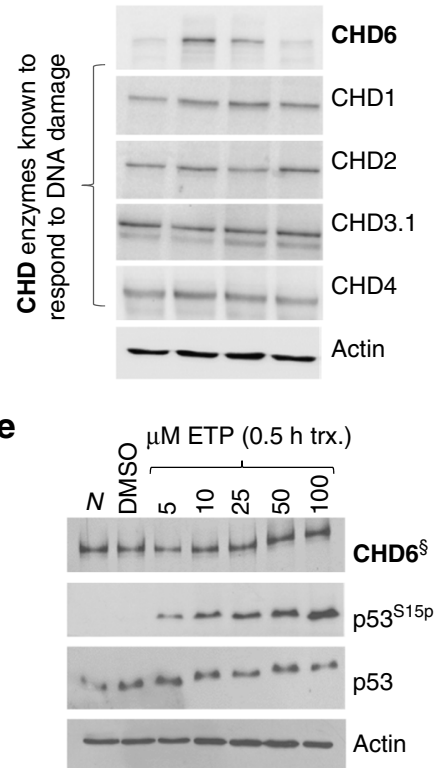

Exposed longer (than normal)

to visualize bands

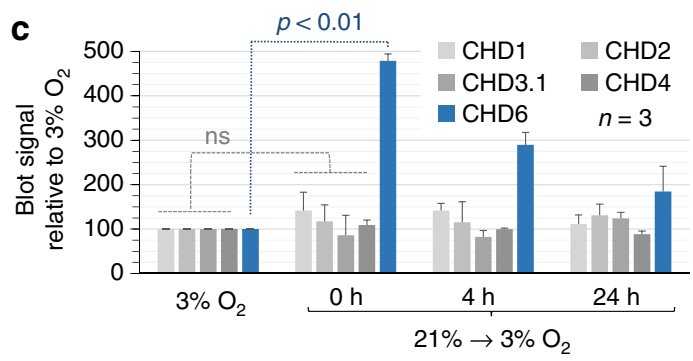

h
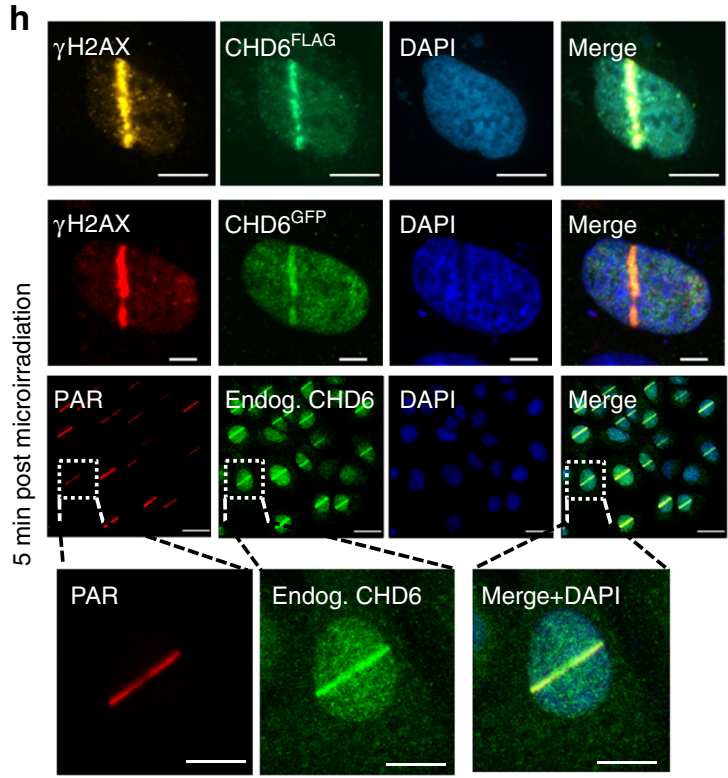

Merge
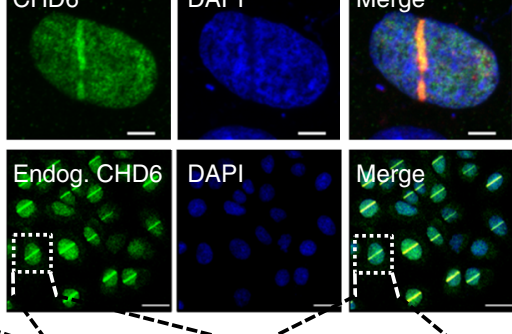

DAPI

Merge

Merge
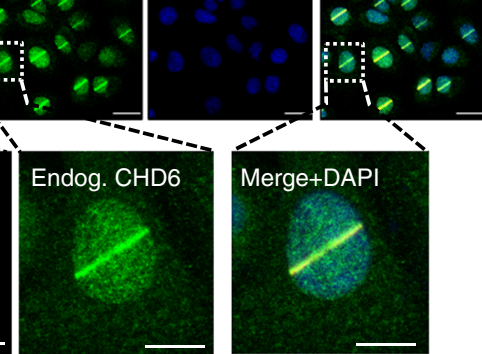

i
PARP1 ${ }^{\text {GFP }}$

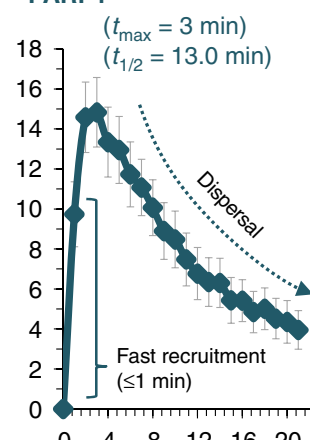

$\begin{array}{llllll}0 & 4 & 8 & 12 & 16 & 20\end{array}$

Time post microirradiation (min)

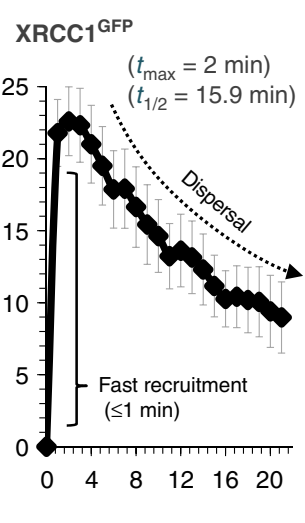

Fig. $1 \mathrm{CHD} 6$ protein levels and localization respond dynamically to oxidative DNA damage. a A549 were cultured at the indicated $\mathrm{O}_{2}$ levels and immunoblotted for CHD6, p53 and actin. Representative blot shown, $n=3$. b Cell extracts from (a) were immunoblotted for CHD1, CHD2, CHD3.1, CHD4 or CHD6 and actin. Representative blot shown. $\mathbf{c}$ Data from (b) was quantified, error bars $=$ s.d.; $n=3$. $P$ values are for Student's $t$-test. $\mathbf{d}$ A549 were exposed $\pm 500 \mu \mathrm{M} \mathrm{H}_{2} \mathrm{O}_{2}$ over $24 \mathrm{~h}$, before extraction and analysis by qPCR for CHD6 mRNA, error bars = s.e.m.; $n=3$. e A549 were exposed to 5-100 $\mu \mathrm{M}$ etoposide (ETP) for $0.5 \mathrm{~h}$ and immunoblotted as in (a) with the addition of $\mathrm{p} 533^{\mathrm{S} 15 p}$. Representative blot shown, $n=3$. $\mathbf{f}, \mathbf{g} \mathrm{A} 549$ were exposed to $\mathrm{H}_{2} \mathrm{O}_{2}$ or $10 \mathrm{~Gy}$ ionizing radiation (IR) \pm bortezomib (BTZ) as indicated and immunoblotted as in (a). Representative blots shown, $n=3$. $\mathbf{h}$ A549 transfected \pm CHD6 GFP/FLAG microirradiated, fixed 5 min later and immunostained for indicated epitopes; scale bars equal $5 \mu$ m. Lower panels show an expanded image of endogenous CHD6 localized at DNA damage tracks; scale bars equal 20 and $5 \mu \mathrm{m}$. i A549 expressing XRCC1 GFP, PARP1GFP or CHD6 GFP were treated as in (h), live imaged over $21 \mathrm{~min}$ and quantified over time as described in Methods. $t_{\mathrm{max}}=$ average time to maximum signal. $t_{1 / 2}=$ average time to $50 \%$ loss of maximum signal. Error bars =s.e.m.; $n=30$ cells. In all cases, \pm refers to with and without

damage tracks was not affected by small molecule inhibition of the DSB signaling protein kinases ataxia telangiectasia mutated (ATM) and/or DNA-dependent protein kinase (DNA-PK; Supplementary Figs. S1b, c). However, inhibition of PAR polymerase (PARP) activity using Olaparib (PARPi) ablated endogenous CHD6 $^{\text {GFP }}$ accumulation (Fig. 3a, b, Supplementary Fig. 1d).
These results were confirmed by depletion of PARP1 and PARP2 by small interfering RNA (siRNA; Fig. 3c, Supplementary Figs. 1e, f). PAR chains are degraded by the PAR glycohydrolase (PARG) and loss or inhibition of PARG activity prolongs PAR longevity, as well as the occupancy of PAR-binding proteins ${ }^{27}$. Endogenous $\mathrm{CHD}^{\mathrm{GFP}}$ occupancy at micro-irradiation tracks was prolonged 
a Site-specific DNA damage recruitment assays

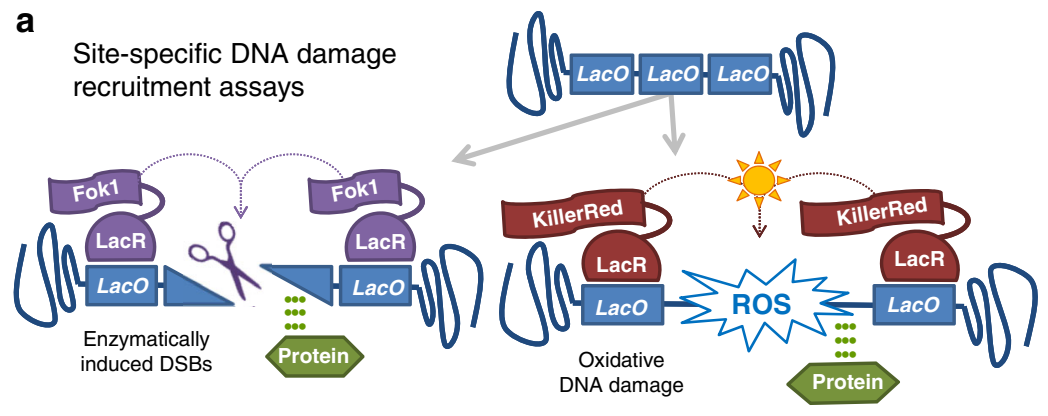

b
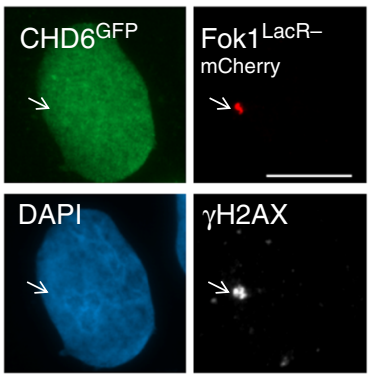

C
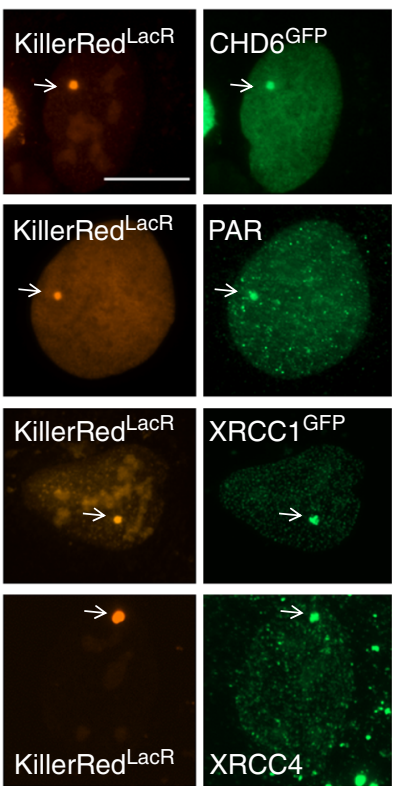
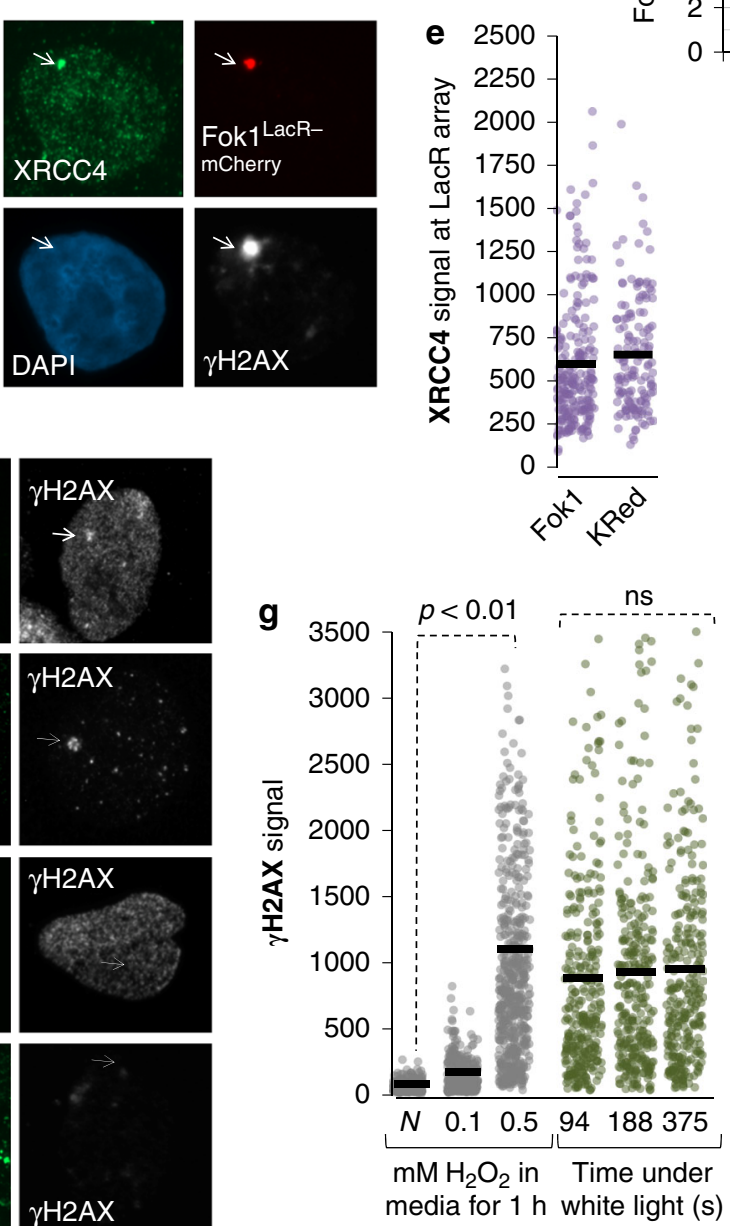
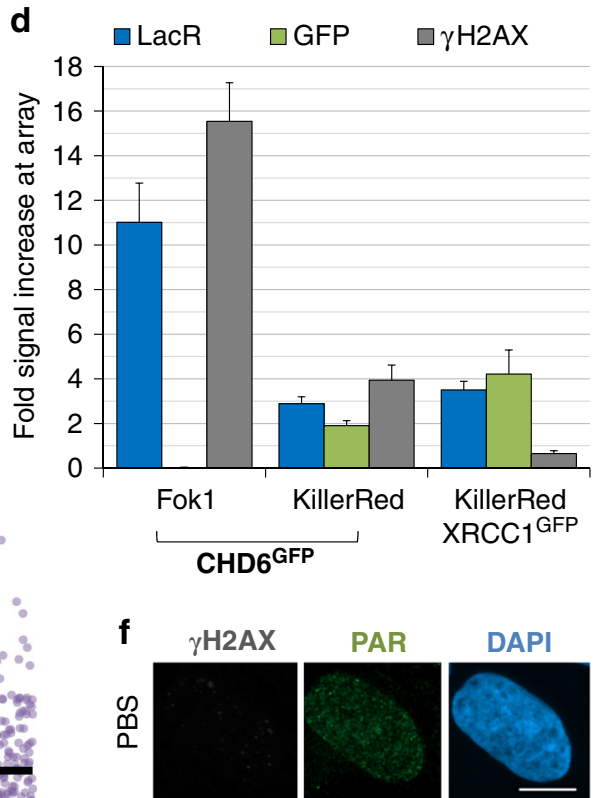

DAPI
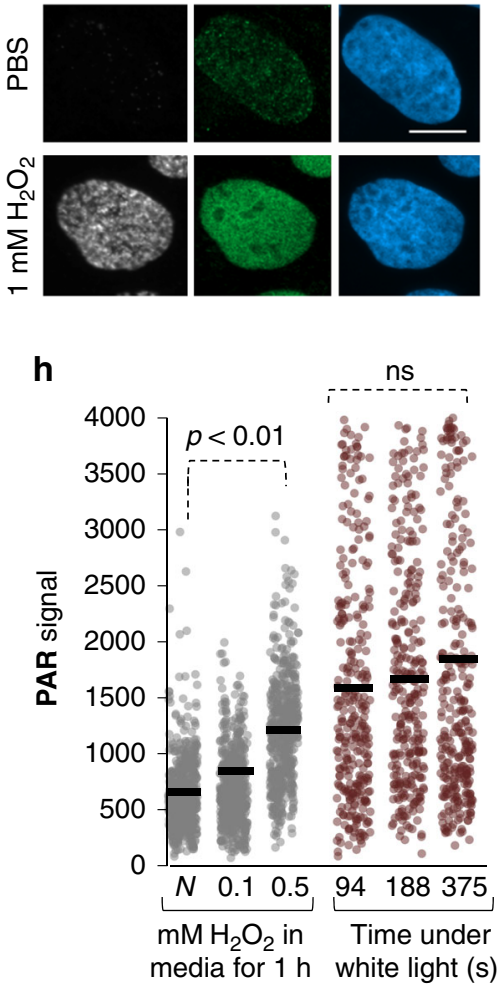

Fig. 2 CHD6 is recruited selectively to oxidative lesions. a Schematic of site-specific DNA damage recruitment assay. b, c Fok1 or KillerRed expression was induced in U2OS 2-6-3 cells (transiently expressing CHD6GFP, XRCC1GFP or neither) then immunostained with $\gamma \mathrm{H} 2 \mathrm{AX}$, PAR and/or XRCC4 and imaged. d, e The fold increase in $\gamma \mathrm{H} 2 \mathrm{AX}$, LaCR, XRCC4, XRCC1 and/or GFP signal in cells from (b, c) was quantified. Error bars $=$ s.e.m.; $n=3$. e-h U2OS 2-6-3 cells were exposed to $1 \mathrm{mM} \mathrm{H}_{2} \mathrm{O}_{2}$ in media for $1 \mathrm{~h}$, immunostained and imaged for nuclear $\gamma \mathrm{H} 2 \mathrm{AX}$ and PAR signal and compared to KillerRed expressing cells stimulated with $94-375$ s of white light. $P$ values are for Student's $t$-test. All scale bars equal $5 \mu m$

in cells treated with PARG inhibitors (PARGi) or PARG siRNA, suggesting that CHD6 binds to PAR directly or to PAR-binding proteins (Fig. $3 \mathrm{a}-\mathrm{c}$ ). XRCC1 is a major PAR-binding platform for recruiting DNA damage response proteins ${ }^{28,29}$ and accumulated fourfold more than CHD6 at micro-irradiation tracks with dissimilar recruitment and dispersal kinetics (Fig. 1i). XRCC1 loss by CRISPR/Cas9 (clustered regularly interspaced short palindromic repeats/CRISPR-associated 9)-mediated deletion did not impact $\mathrm{CHD6}^{\mathrm{GFP}}$ recruitment, suggesting that $\mathrm{CHD} 6$ binds to PAR directly or indirectly via an XRCC1-independent process (Supplementary Fig. 1g).

To interrogate the specific regions of CHD6 required for recruitment to DNA damage sites, we introduced multiple point or truncation mutations without perturbing nuclear localization (Fig. 3d, Supplementary Fig. 1h). Ablation of a conserved catalytic amino acid (K492A) had no impact on CHD6 dynamics (Fig. 3e). Introduction of point mutations into highly conserved amino acids (F318A, Y322A, Y398A, W402A $=\Delta \mathrm{CD} 1+2)$ known to ablate CHD enzyme ability to bind methyl-lysine ${ }^{30,31}$ perturbed mid-to-late retention at DNA damage, although it had no effect on the early/fast recruitment (Fig. 3e). Deletion of the C-terminal BRK domain (1-1448) had no effect on CHD6 dynamics, while additional loss of the SANT domain (1-1028) and/or the ATPase/ Helicase core (1-449) only impacted late retention (Fig. 3e). Further loss of the double chromodomain ablated the later accumulation and retention of CHD6 (1-269), suggesting (similar 
a

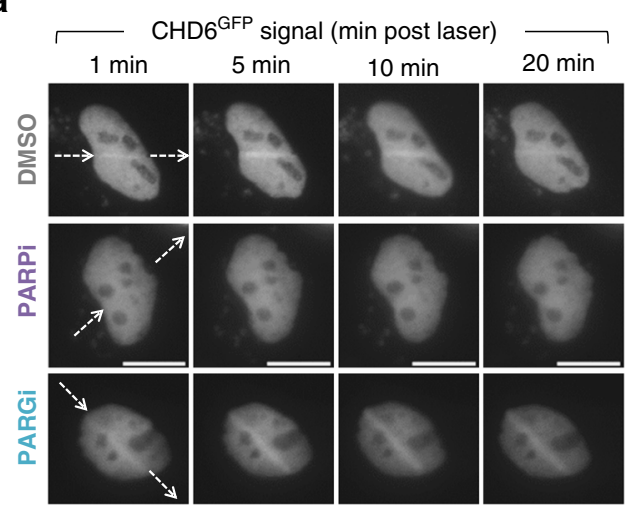

b

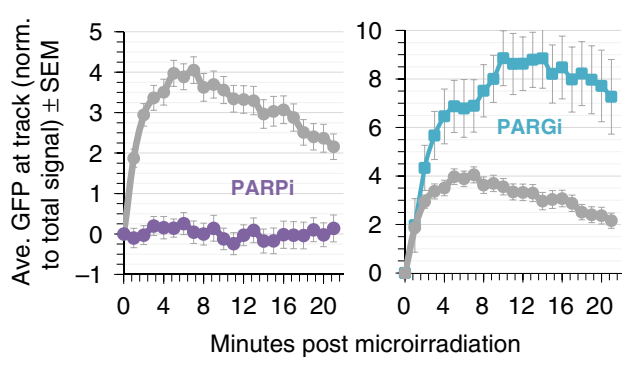

C
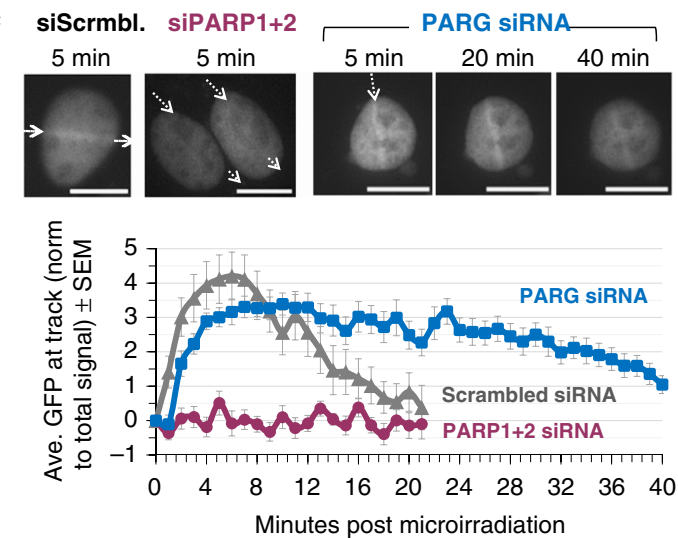

d

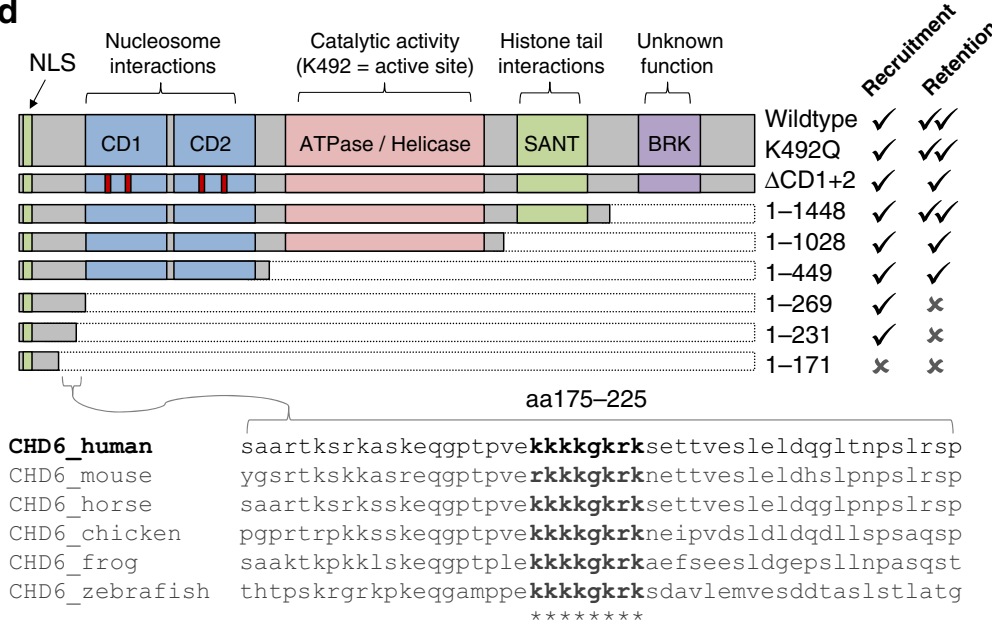

e
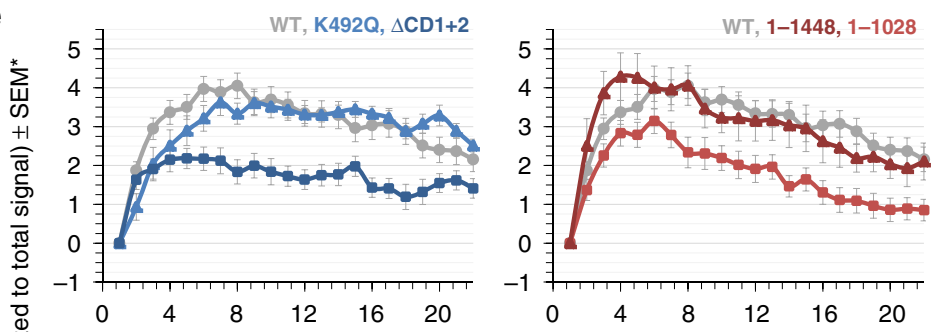

*NB: full statistics in Minutes post microirradiation suppl. Fig 1i
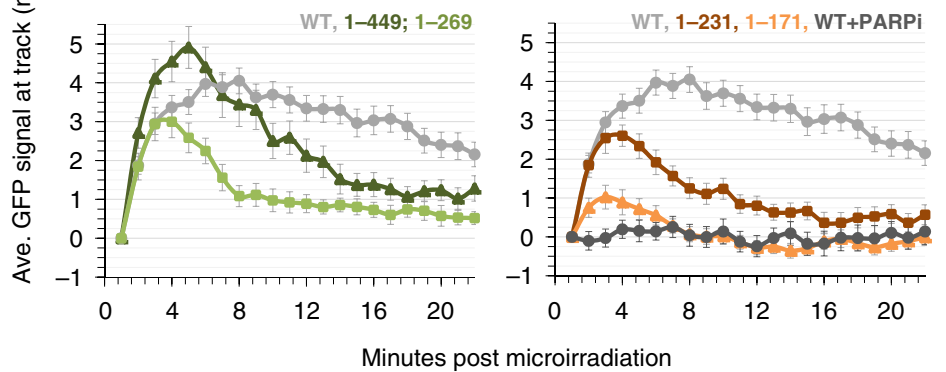

Fig. 3 CHD6 recruitment to DNA damage is PAR-dependent. a A549 expressing CHD6GFP were treated with DMSO, PARP inhibitor (PARPi) or PARG inhibitor (PARGi) for $1 \mathrm{~h}$ before micro-irradiation and live imaging over $21 \mathrm{~min}$. Scale bars equal $10 \mu \mathrm{m}$. b Cells were quantified for GFP signal increase within the laser track as described in Methods. Gray lines indicate DMSO-treated cells; purple lines indicate PARPi-treated cells; cyan lines indicate PARGi-treated cells. Error bars = s.e.m.; $n=8-30$. c A549 were transfected with indicated siRNAs and CHD6GFP; 16 h later, cells were microirradiated and live imaged and quantified as in $(\mathbf{a}, \mathbf{b})$. Scale bars equal $10 \mu \mathrm{m}$. Gray lines indicate scrambled siRNA-treated cells; magenta lines indicate PARP1 and PARP2 siRNA-treated cells; blue lines indicate PARG siRNA-treated cells. Error bars =s.e.m.; $n=20$. d Schematic of known CHD6 domains, including: catalytic dead (K492Q), double chromodomain $(\Delta C D 1+2)$ and truncation mutations. Cross-species alignment of the PAR-dependent recruitment region is expanded. e A549 expressing CHD6 mutants indicated in (d) were treated and analyzed as in (a, b). All error bars = s.e.m.; $n=12-53$. Full statistical analysis for data in all panels is in Supplementary Table 1. Line colors are as follows: gray $=W T$; light blue $=K 492$; dark blue $=\Delta C D 1+2$; dark red $=1-1448$; light red $=1-1028$; dark green $=1-449$; light green $=1-269$; dark orange $=1-231$; light orange $=1-171$; dark gray $=$ WT treated with PARPi

to the $\Delta \mathrm{CD} 1+2$ mutant) that the double chromodomain is required for the second phase of CHD6 relocalization to sites of DNA damage, after initial PAR-dependent recruitment (Fig. 3e). Further deletion analysis revealed that the early, fast, PARdependent recruitment of CHD6 was attributable to aa171-231, with the 1-171 mutant unable to relocalize to DNA damage (Fig. 3e) and statistically similar to PARPi-treated cells expressing wild-type CHD6 (Supplementary Table 1). This 60-amino acid (aa) region contains a single, highly conserved, positive KR-rich patch similar to regions that enable electrostatic interactions with PAR in other proteins ${ }^{32}$ (Fig. 3d). Collectively, these data show that CHD6 is recruited to DNA damage sites in a manner dependent initially on its N-terminal PAR-dependent binding region, and then retained subsequently via its double chromodomain and SANT domain.

To corroborate our micro-irradiation data with an alternative approach, we next attempted to examine whether CHD6 interacts with endogenous PAR by pulling down GFP or CHD6 GFP. We used HEK293 cells, as A549 displayed insufficient transfection efficiency. Cells were treated with PARGi (to block PAR degradation) and $\mathrm{H}_{2} \mathrm{O}_{2}$ to stably induce PAR; however, we found that PAR was strongly suppressed by $\mathrm{CHD}^{\mathrm{GFP}}$ over-expression, precluding the experiment (Supplementary Fig. 1i). We speculated that this might represent suppressed ROS-induced DNA damage (and hence PAR) when CHD6 is in abundance. Alternatively, we expressed GFP or GFP-tagged CHD6 or 
CHD4 (as a positive control) and incubated extracts with streptavidin-agarose loaded with biotin alone, PAR-biotin or $\mathrm{H} 3^{\mathrm{K} 9 m e 3}$-biotin (a canonical CHD-binding epitope), and immunoblotted for GFP. GFP-tagged CHD6 and CHD4 (but not GFP alone) were present in $\mathrm{PAR}$ - or $\mathrm{H}_{3}{ }^{\mathrm{K} 9 \mathrm{me} 3}$-biotin pulldowns, but not biotin alone (Supplementary Fig. 1j). This confirmed our observations using lasers, demonstrating that CHD6 displays PAR-dependent binding activity.

CHD6 ablation leads to elevated PAR during oxidative stress. To assess the significance of CHD6 expression under resting and oxidative stress conditions, we perturbed CHD6 in A549 cells using CRISPR/Cas9-mediated gene editing ( $\triangle \mathrm{CHD}$ 6). This ablated endogenous CHD6 by immunofluorescence or immunoblot, was comparatively superior to siRNA-based depletion (in terms of endogenous CHD6 signal loss) and also validated CHD6 antibody specificity (Fig. 4a). Single cell cloned A549 ${ }^{\triangle \mathrm{CHD}}$ lines were analyzed by multiple independent gene sequencing runs, indicating a 100 nucleotide deletion from both $\mathrm{CHD} 6$ alleles. PCR amplification of the guide RNA target region confirmed a deletion within CHD6 exon 2 (Supplementary Fig. 2a), while immunofluorescence confirmed protein loss and our ability to re-express CHD6GFP ectopically (Fig. 4a, Supplementary Fig. 2b). A549 ${ }^{\triangle \mathrm{CHD}} 6$ were viable, grew well under unstressed conditions and, by fluorescence-activated cell sorting (FACS) analysis, showed no abnormalities in the cell cycle phase distribution of asynchronous populations (Supplementary Fig. 2c, d). The expression of PARP1 and its relocalization to DNA damage was unaltered in $\mathrm{A} 549^{\triangle \mathrm{CHD} 6}$ (Supplementary Figs. 2e, f). The CHD1, CHD2, CHD3.1 and CHD4 expression also remained unchanged (Supplementary Fig. 2g). We next ascertained whether PAR induction was indeed altered by CHD6 expression status, as our earlier result implied (Supplementary Fig. 1i). We were unable to generate lines stably overexpressing CHD6, due to repeatedly observed silencing of CHD6 constructs during selection. Hence, we relied upon transient transfection to rescue A549 ${ }^{\triangle \mathrm{CHD}} 6$ phenotypes. As before, PARGi was used to stabilize PAR. PAR induction by $\mathrm{H}_{2} \mathrm{O}_{2}$ was $\sim 2$-fold greater in A549 ${ }^{\Delta \mathrm{CHD}} 6$ compared to controls by immunoblot or immunofluorescence, and this was suppressed by $\mathrm{CHD}^{\mathrm{GFP}}$, but not GFP or CHD4GFP overexpression (Fig. 4b-d, Supplementary Fig. 3a, b), indicating the genetic specificity of our system. Similar effects were observed in the absence of PARGi, albeit with much weaker signal (Supplementary Fig. 3c). CHD6GFP over-expression (but not GFP or CHD4GFP) also suppressed PAR in wild-type cells (Fig. 4b-d, Supplementary Fig. 1i), fitting with earlier results. CHD6 ${ }^{\triangle \mathrm{CD} 1+2}$ failed to complement A549 $\triangle \mathrm{CHD} 6$, suggesting that retention at sites of oxidative DNA damage is functionally important. CHD6 mutated in the ATPase/helicase domain (K492Q) also failed to complement A549 $\mathrm{CHD6}$, suggesting that CHD6 catalytic activity is necessary for its role in regulating the oxidative DNA damage response (Fig. 4d). These data indicate a role for CHD6 in controlling PAR induction following oxidative stress-induced DNA damage, an activity that involves both its ability to remodel chromatin and to be retained at sites of oxidative DNA damage.

Cells lacking CHD6 have diminished antioxidant responses. PAR formation is triggered by oxidative DNA damage and to directly measure the intrinsic cellular oxidative stress of CHD6deleted cells, we incubated cells with chemically reduced (nonfluorescent) 2',7'-dichlorodihydrofluorescein diacetate $\left(\mathrm{H}_{2}\right.$ DCFDA) which, upon oxidation, converts to fluorescent 2',7'dichlorofluorescein (DCF) and measured fluorescence $\pm \mathrm{H}_{2} \mathrm{O}_{2}$ by FACS (Fig. 4e). In the resting state, A549 $\triangle \mathrm{CHD} 6$ populations contained 1.65-fold more DCF-positive cells relative to wild type and 2.9-fold more following $\mathrm{H}_{2} \mathrm{O}_{2}$, confirming a state of elevated cellular oxidative stress in the absence of CHD6 (Fig. 4e). Wildtype CHD6mPLUM (GFP could not be used, as it interfered with green DCF signal) complemented the elevated oxidative stress observed in A549 $\triangle$ CHD6 cells treated with $\mathrm{H}_{2} \mathrm{O}_{2}$, further confirming specificity (Fig. 4e). Little is known about the detailed molecular consequences of CHD6 deletion, although there is one report of a yeast-two-hybrid interaction between CHD6 and $\mathrm{Nrf}^{33}$, which is important in controlling antioxidant transcriptional events ${ }^{34}$. To explore this using our validated human genetic model of CHD6 deletion, we used qPCR to measure Nrf2 gene target expression after chronic $\mathrm{H}_{2} \mathrm{O}_{2}$ over $24 \mathrm{~h}$. This included genes highly responsive to $\mathrm{H}_{2} \mathrm{O}_{2}$ : HMOX1 (heme oxygenase 1), a regulator of iron homeostasis and Fenton reactions producing $\mathrm{OH}$ radicals from $\mathrm{H}_{2} \mathrm{O}_{2}$, and TXNRD1 (thioredoxin reductase 1) that regenerates thioredoxin following reduction of proteins oxidized by $\mathrm{OH}$ radicals. While $H M O X 1$ and TXNRD1 gene expression both increased within 4-8 h of $\mathrm{H}_{2} \mathrm{O}_{2}$ in wild-type cells, there was suppressed baseline expression and comparatively lowto-no increased expression after $\mathrm{H}_{2} \mathrm{O}_{2}$ in A549 $\triangle \mathrm{CHD} 6$ (Fig. 4f). We also examined the expression of two other Nrf2 targets: NQO1 (NADPH:Quinine Oxidoreductase 1) involved in oquinone detoxification and G6PD (glucose-6-phosphate dehydrogenase) involved in NADPH synthesis. There was no $\mathrm{H}_{2} \mathrm{O}_{2}$ inducible increase in NQO1 or G6PD expression, indicating these genes are not upregulated by $\mathrm{H}_{2} \mathrm{O}_{2}$ in these cells, with minor to insignificant differences in A549 $\triangle \mathrm{CHD} 6$ (Fig. 4f, g, Supplementary Fig. 3d). To control for confounding effects on transcription in general, we examined TBP, a gene unrelated to oxidative stress; there was no change in TBP expression with $\mathrm{H}_{2} \mathrm{O}_{2}$ or in A549 ${ }^{\triangle C H D 6}$ versus wild type (Fig. $4 \mathrm{~g}$ ). PARP inhibition had no impact on $\mathrm{H}_{2} \mathrm{O}_{2}$-induced $H M O X 1$ or TXNRD1 induction, indicating that this role of CHD6 is likely distinct to its PARdependent DNA damage recruitment (Supplementary Fig. 4a). To assess the impact of antioxidant gene expression on the A549 ${ }^{\triangle \mathrm{CHD}} 6$ phenotype, we transiently over-expressed GFP-tagged HMOX1 and assessed PAR induction after $\mathrm{H}_{2} \mathrm{O}_{2}$ as in Fig. 4d. At even low to moderate levels of expression, HMOX1 GFP (but not GFP alone) suppressed the elevated PAR induction phenotype of A549 $\triangle \mathrm{CHD} 6$ (Fig. 5a). These data are indicative of a role for $\mathrm{CHD} 6$ in the antioxidant transcriptional response involving a sub-pathway of Nrf2-controlled gene expression, and may partly explain how CHD6 controls PAR formation after oxidative stress.

CHD6 loss elevates DNA damage with no overt DNA repair defect. Elevated oxidative stress, reduced anti-oxidants and exaggerated PAR induction are all suggestive of increased DNA breakage that can be monitored by comet assays and immunofluorescence of $\gamma \mathrm{H} 2 \mathrm{AX}$ or 53BP1 foci ${ }^{35}$. Alkaline comet assays to measure SSB induction and repair revealed an increase in SSBs formed after $\mathrm{H}_{2} \mathrm{O}_{2}$ in $\mathrm{A} 549^{\Delta \mathrm{CHD} 6}$ relative to controls (Fig. 5b, c), albeit there was no significant change in actual SSB repair (Fig. 5d). 53BP1 foci per cell, with a wide distribution within a population, increased with acute $\mathrm{H}_{2} \mathrm{O}_{2}$ exposure and were also markedly higher in A549 $\triangle \mathrm{CHD6}$ (Fig. 5e). Looking at foci per cell over time, 53BP1 foci resolution was not impacted by CHD6 loss, consistent with a role in suppressing DNA damage induction, rather than DSB repair itself. A similar, although much more subtle, phenotype was observed after IR exposure (Fig. 5f). This further contrasts the role of CHD6 within the DNA damage response from CHD1-CHD4, the loss of any of which impacts DSB repair capacity ${ }^{3-13}$. To more comprehensively determine the DNA repair capacity in the absence of CHD6, we used fluorescence multiplex host cell reactivation (FM-HCR) assays to 
a

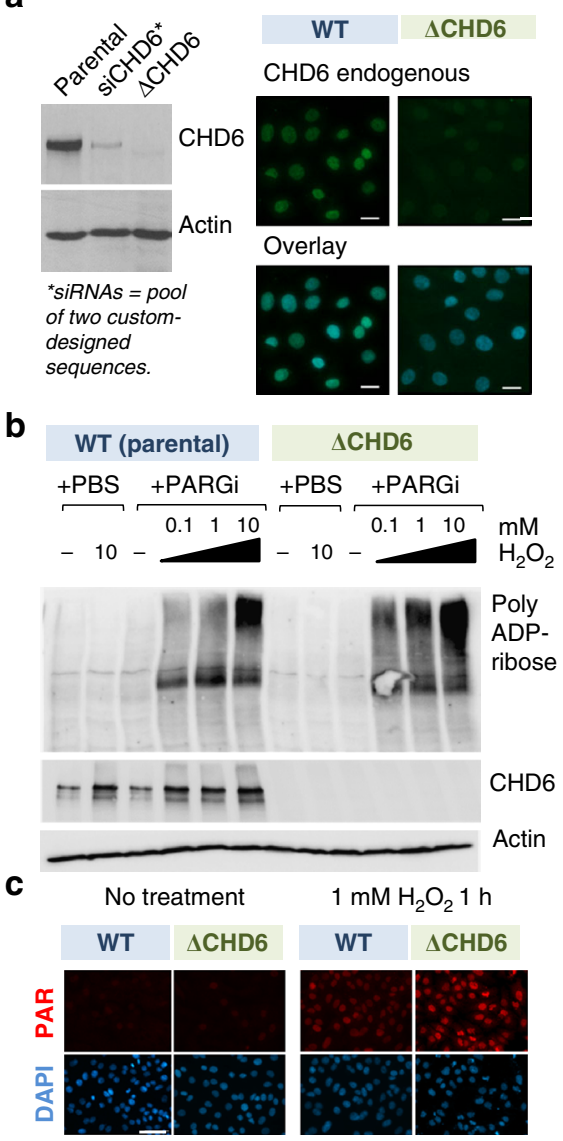

$\triangle \mathrm{CHD} 6$ cells, $1 \mathrm{mM} \mathrm{H}_{2} \mathrm{O}_{2}$ in media $1 \mathrm{~h}$

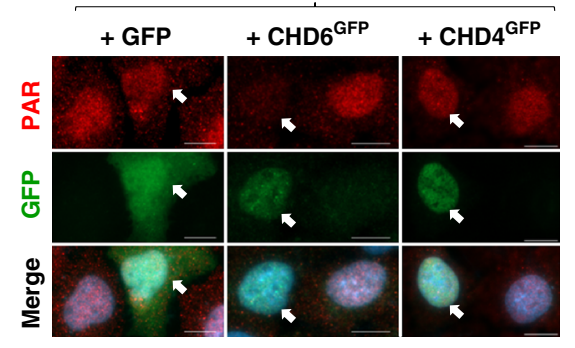

d

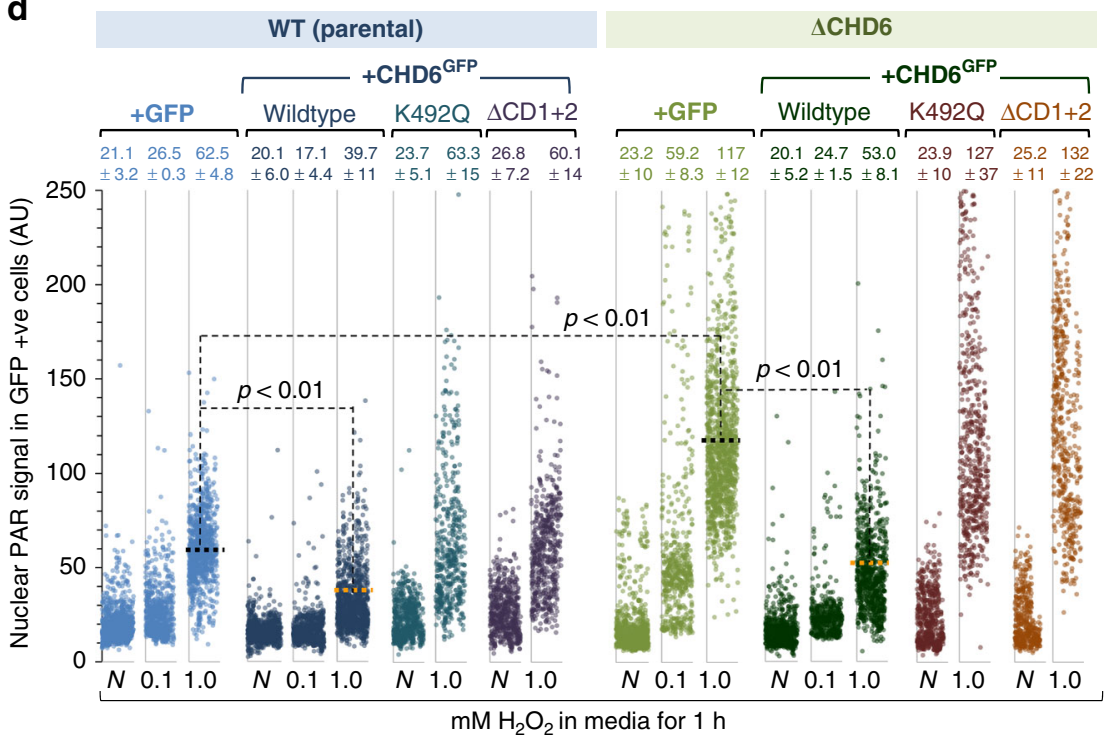

e

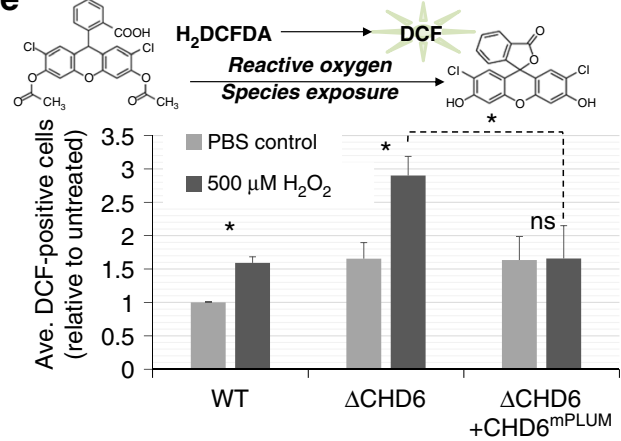

f

g

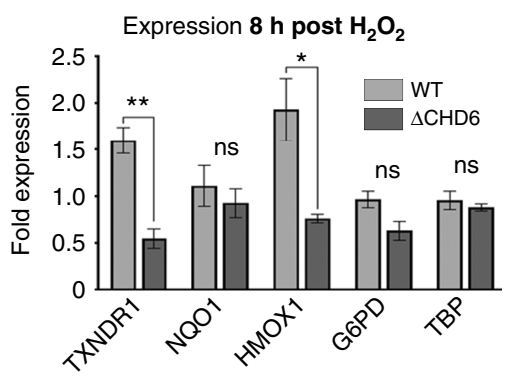

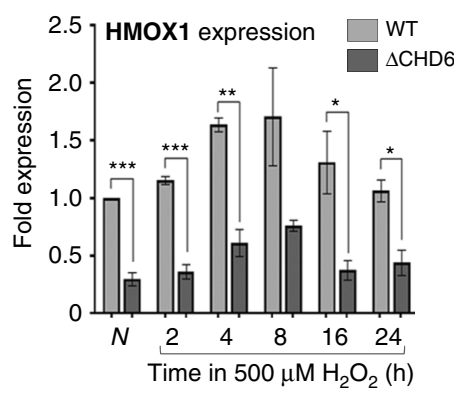

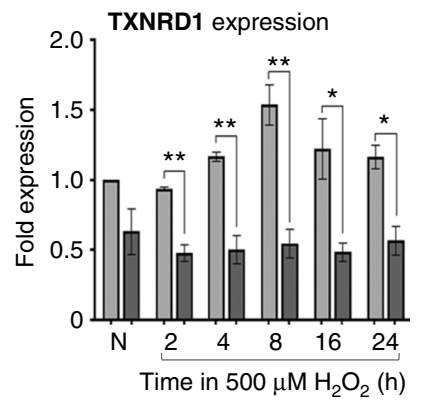

Fig. 4 Cells lacking CHD6 display elevated PAR, oxidative stress and have diminished antioxidant responses. a A549 were subjected to CRISPR-mediated CHD6 gene ablation ( $\triangle$ CHD6) or treated with CHD6 siRNA (siCHD6) before being immunoblotted (left) or immunostained (right) as indicated. Parental refers to the wild-type (WT) A549 used to derive $\Delta$ CHD6. Scale bars $=20 \mu \mathrm{m}$. b WT and A549 $\Delta \mathrm{CHD} 6$ were treated $\pm 5 \mu \mathrm{M}$ PARGi and indicated $\mathrm{H}_{2} \mathrm{O}_{2}$ doses for $1 \mathrm{~h}$ before immunoblotting for PAR, CHD6 and actin. Representative blot shown, $n=3$. c WT and $\Delta$ CHD6 A549 were complemented with GFP, CHD6GFP or CHD4GFP and treated with $5 \mu \mathrm{M}$ PARGi $\pm 1 \mathrm{mM} \mathrm{H}_{2} \mathrm{O}_{2}$ in media for $1 \mathrm{~h}$ before immunostaining for PAR (red) and DAPI (blue). Lower panels highlight GFP-expressing cells. Scale bars $=10 \mu \mathrm{m}$. d WT and A549 $\triangle \mathrm{CHD6}$ were transfected with GFP, or GFP-tagged CHD6wildtype, CHD6 4 chromo or $\mathrm{CHD6}^{\mathrm{K} 492 \mathrm{Q}}$ before treatment with $5 \mu \mathrm{M}$ PARGi $\pm 0-1 \mathrm{mM} \mathrm{H}_{2} \mathrm{O}_{2}$ for $1 \mathrm{~h}$ and immunostaining for PAR and GFP as in (c). Nuclear PAR in $>1000$ GFP-positive cells $(n=3)$ was quantified using ImageJ. Dot colors represent: light blue $=$ GFP alone, WT cells; dark blue $=$ WT CHD6GFP, WT cells; cyan $=$ K492Q CHD6 GFP, WT cells; purple $=\Delta \mathrm{CD} 1+2 \mathrm{CHD6}{ }^{\mathrm{GFP}}, \mathrm{WT}$ cells; light green $=$ GFP alone, $\Delta \mathrm{CHD6}$ cells; dark green $=$ WT CHD6 GFP, $\Delta$ CHD6 cells; dark red $=$ $\mathrm{K} 492 \mathrm{Q}$ CHD6 GFP,$\Delta \mathrm{CHD6}$ cells; orange $=\Delta \mathrm{CD} 1+2 \mathrm{CHD6}{ }^{\mathrm{GFP}}, \Delta \mathrm{CHD6}$ cells. Error bars = s.e.m.; $n=3$. e WT, A549 $\Delta \mathrm{CHD6}$ and A549 $\Delta \mathrm{CHD} 6$ complimented with CHD6mPLUM, incubated with $\mathrm{H}_{2}$ DCFA then exposed $\pm 0.5 \mathrm{mM} \mathrm{H}_{2} \mathrm{O}_{2}$ for $1 \mathrm{~h}$ and FACS analysis of green fluorescent DCF signal. Data represent an average of the percent DCF-positive cells within a population, expressed relative to the PBS-treated wild-type control. Error bars $=s . e . m . ; n \geq 3$. $\mathbf{f}, \mathbf{g}$ WT and A549 $\triangle \mathrm{CHD6}$ were exposed to $\pm 500 \mu \mathrm{M} \mathrm{H}_{2} \mathrm{O}_{2}$ in media for up to 1 day and analyzed by qPCR to ascertain HMOX1, TXNRD1, NQO1, G6PD and TBP mRNA expression. Error bars =s.e.m.; $n=3$. In all cases, $P$ values are for Student's $t$-test: ns not significant $(P>0.05)$; ${ }^{\star} P<0.05 ;{ }^{\star \star} P<0.01 ;{ }^{\star \star \star} P<0.001$. In all cases, \pm refers to with and without 
a

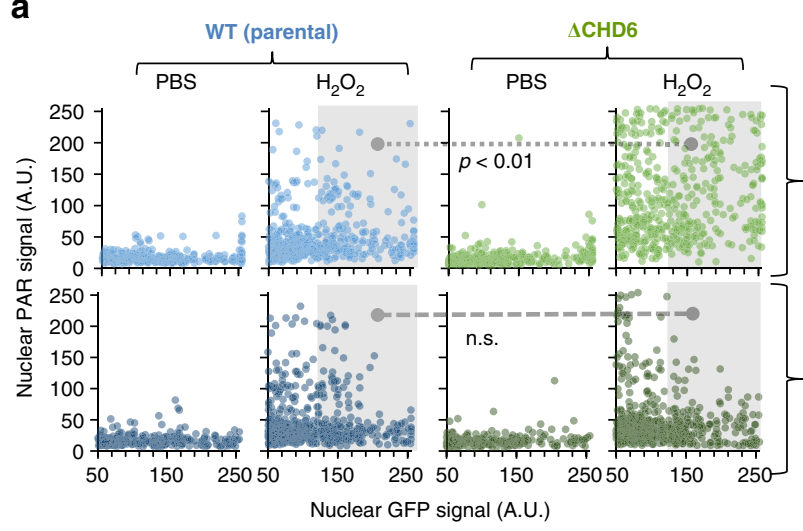

(GFP signal \pm DAPI)

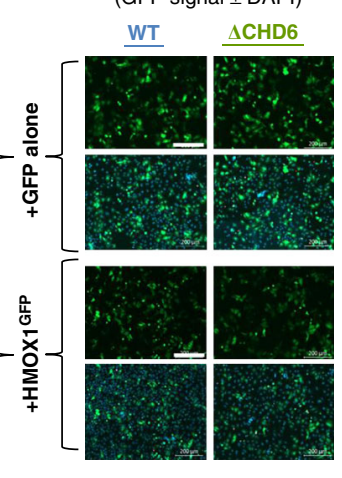

b

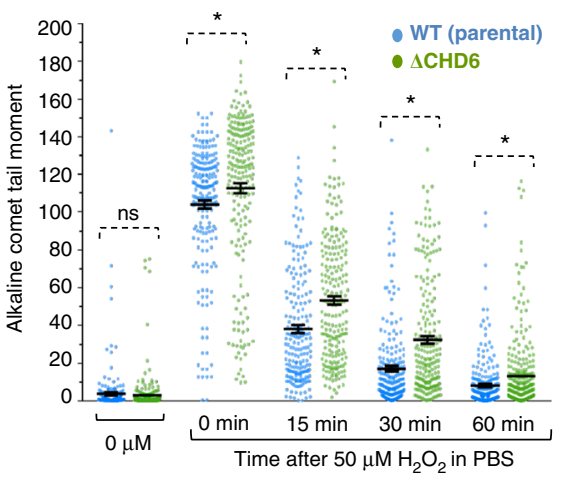

C

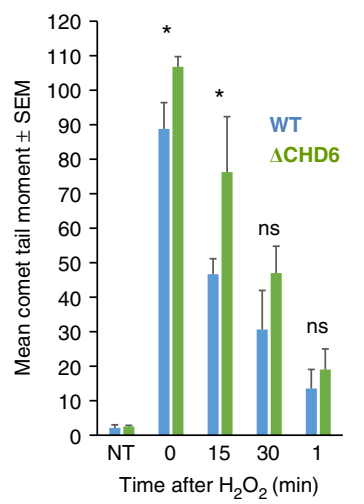

d

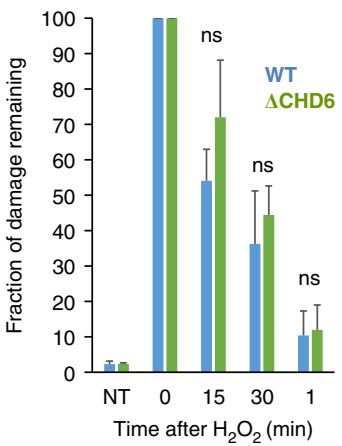

$\mathbf{g}$

e

45
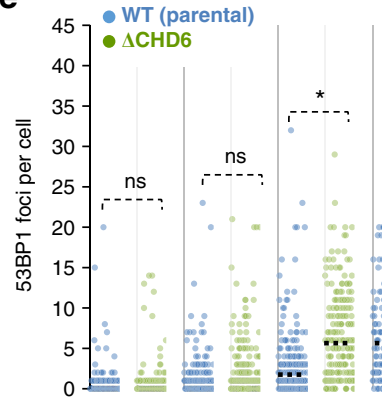

f

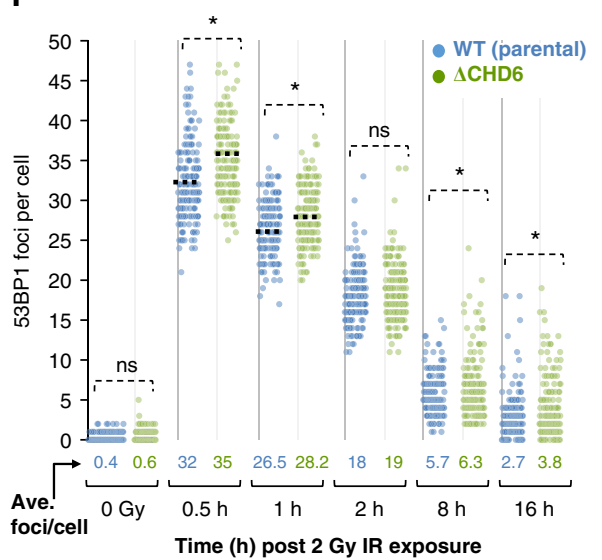

Repair capacity (relative to wildtype)

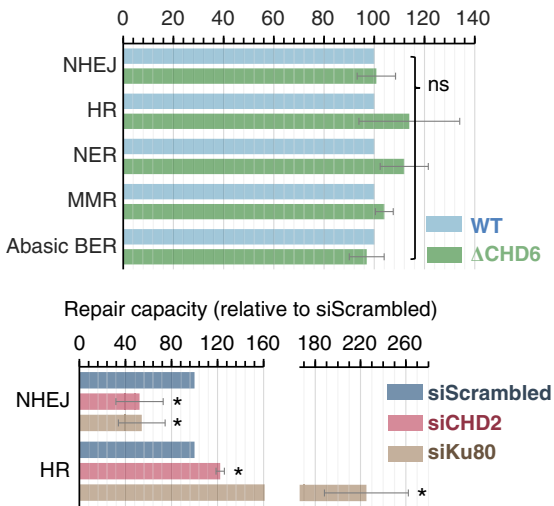

h

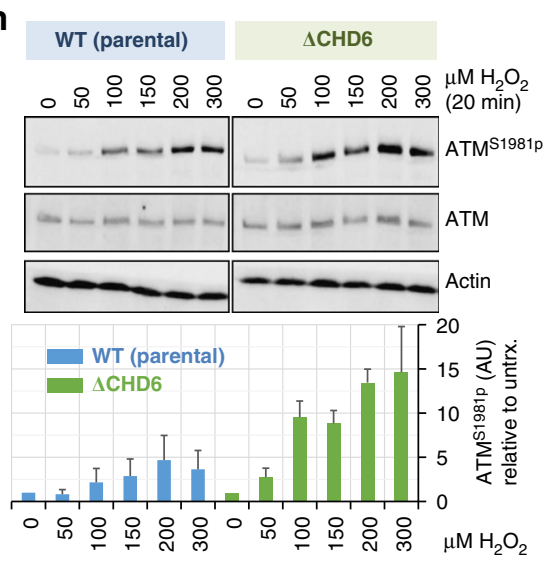

Fig. 5 CHD6-deficient cells display increased single-strand breakage, DNA damage signaling but normal DNA repair capacity. a WT and $\triangle$ CHD6 A549 were transfected with GFP or HMOX 1 GFP and treated with $5 \mu \mathrm{M}$ PARGi $\pm 1 \mathrm{mM} \mathrm{H}_{2} \mathrm{O}_{2}$ in media for $1 \mathrm{~h}$ before immunostaining for PAR. Nuclear PAR and GFP signal was quantified by ImageJ. Right panels = representative images indicating GFP (green) and/or DAPI (blue) signal in each condition. b-d WT and $\triangle$ CHD6 A549 in suspension were treated with $50 \mu \mathrm{M} \mathrm{H}_{2} \mathrm{O}_{2}$ and analyzed by alkaline comet assay as in Methods; b raw data from single experiment; c mean comet tail moment for $n=3$; error bars =s.e.m.; $\mathbf{d}$ data normalized to induced damage ( 0 min time point). Error bars $=$ s.e.m. e WT and A549 $\triangle \mathrm{CHD6}$ were exposed to $0-300 \mu \mathrm{M} \mathrm{H}_{2} \mathrm{O}_{2}$ in PBS for $20 \mathrm{~min}$, washed, returned to media for 0.5-8 h, fixed and immunostained for 53BP1. 53BP1 foci per cell were enumerated for $>50-100$ cells per $n, n=3$. Graph indicates scatters of foci per cell across population; average number of foci per cell are indicated. f Cells from (a) were irradiated and harvested at indicated time points, then processed and analyzed as in (a). $\mathbf{g}$ (Top) WT, A549 4 CHD6 were incubated for $4 \mathrm{~h}$ at $3 \% \mathrm{O}_{2}$ for acclimatization and transfected with FM-HCR reporter plasmids (see Methods). A549 4 CHD6 repair capacity for each substrate was normalized to WT values, and is represented as relative repair capacity. (Bottom) A549 were transfected (48 h earlier) with scrambled, CHD2 or Ku80 siRNA, and transfected $48 \mathrm{~h}$ later with FM-HCR plasmids. Error bars = s.e.m.; $n=3$. $\mathbf{h}$ WT and A549 4 CHD6 were exposed to $0-300 \mu M$ $\mathrm{H}_{2} \mathrm{O}_{2}$ in PBS for 20 min, washed, returned to media for $0.5 \mathrm{~h}$ and immunoblotted for ATM ${ }^{51981 \mathrm{p}}$, ATM and actin. Average signal from $n=3$ is indicated in lower panel, error bars $=$ s.d. In all cases, $P$ values are for Student's $t$-test: ns not significant $(P>0.05) ;{ }^{\star} P<0.05$. In all cases, \pm refers to with and without, blue refers to WT cells; green refers to $\triangle$ CHD6 cells 
measure: (i) non-homologous end-joining (NHEJ)-mediated DSB repair, (ii) homologous recombination (HR)-mediated DSB repair, (iii) nucleotide excision repair (NER) of ultraviolet Cinduced DNA lesions, (iv) mismatch repair (MMR) of a G:G mispair and (v) BER of a tetrahydrofuran abasic site analog. In brief, fluorescent reporter plasmid substrates containing controlled quantities of each specific lesion are transfected into cells, whereupon DNA repair alters fluorescent reporter signal detectable by flow cytometry; these assays have been validated previously ${ }^{36-38}$. CHD6 deletion did not significantly impact NHEJ or HR-mediated DSB repair or BER pathways requiring SSB repair (Fig. 5g), fitting with 53BP1 foci kinetic and comet assay data. As controls, we depleted either CHD2 or Ku80 by siRNA and observed an expected ${ }^{3}$ reduction in NHEJ and/or increase in HR. Ku80 knockdown confirms the ability of FM-HCR to detect siRNA-induced DSB repair defects, while CHD2 knockdown indicates that FM-HCR is sensitive to altered CHD status at least for NHEJ and HR endpoints (Fig. 5g). No defects in MMR, NER or BER-mediated DNA repair were observed in A549 $\triangle \mathrm{CHD} 6$ relative to wild type using FM-HCR, and although this will require future work to confirm, it suggests that CHD6 may not play a role in these DNA repair pathways.

Cells lacking CHD6 display amplified DSB signaling. Fitting with increased induction of oxidative DNA damage, A549 $\triangle$ CHD6 displayed greater ATM $^{\text {S1981p }}$ signal (a marker of DSB-induced ATM protein kinase signal activation) for a given dose of $\mathrm{H}_{2} \mathrm{O}_{2}$ compared to controls (Fig. 5h). This was further supported by a cell-by-cell analysis of $\mathrm{H} 2 \mathrm{AX}{ }^{\mathrm{S} 139 \mathrm{p}}$ and KAP1 ${ }^{\mathrm{S} 824 \mathrm{p}}$ signal, both downstream readouts of ATM signaling activity ${ }^{39}$ and, for a range of $\mathrm{H}_{2} \mathrm{O}_{2}$ doses and time points, the signal intensity of $\mathrm{H} 2 \mathrm{AX}{ }^{\mathrm{S} 139 \mathrm{p}}$ and KAP1 $1^{\mathrm{S} 824 \mathrm{p}}$ were both greater in A549 ${ }^{\triangle \mathrm{CHD} 6}$ versus controls (Fig. 6a). To explore whether this increase in DSB response signal transduction impacted cell cycle checkpoint arrest, a primary functional endpoint of the DSB response, we monitored $\mathrm{H} 3{ }^{\mathrm{S} 10 \mathrm{p}}$ and nuclear morphology as a read out of mitotic entry, distinguishing $\mathrm{G} 2$ from $\mathrm{M}$ phase in asynchronous populations $\mathrm{s}^{40}$. Complete G2/M checkpoint arrest was observed in A549 ${ }^{\Delta \mathrm{CHD} 6}$ at $\mathrm{H}_{2} \mathrm{O}_{2}$ doses too low to trigger complete arrest in controls (Fig. 6b). At doses and times with the largest differences in G2/M arrest, only minor differences in 53BP1 foci/cell were seen, suggesting checkpoint hypersensitivity in A549 $\triangle$ CHD6 cannot be explained entirely by DSB numbers. To explore this further, we repeated this experiment using IR (Fig. 6b), observing a similar hypersensitive arrest phenotype with little difference in 53BP1 foci and, by re-plotting data as mitotic index relative to foci number/cell, we determined that A549 $\triangle \mathrm{CHD} 6$ showed a 2-3-fold increase in $\mathrm{G} 2 / \mathrm{M}$ checkpoint sensitivity regardless of DSB number or source (Supplementary Fig. 4b). These findings suggest that CHD6 may have a pleiotropic impact on oxidative DNA damage responses, potentially involving suppression of damage induction (via antioxidant upregulation) and/or modulating ATM signaling to define cell cycle checkpoint arrest sensitivities.

CHD6 regulates chromatin compaction distinct from CHD3. We hypothesized that a disrupted chromatin state may contribute to amplified DNA damage signaling of CHD6-ablated cells-in essence, a multiplying effect alongside increased oxidative damage induction. The sensitivities of DNA damage response endpoints (such as cell cycle checkpoint arrest) are generated by the signal transduction mechanisms of the cell phase in question; for example, the G2/M checkpoint requires ATM signaling produced by 10 or more DSBs to remain $100 \%$ active, below which signaling is insufficient to withhold cells from mitosis ${ }^{40}$. Cells with abnormally relaxed chromatin are known to display hypersensitive G2/M checkpoint activation, as ATM signaling per DSB is increased in the absence of the dampening effect of nucleosome compaction ${ }^{41}$. Comprehensive mass spectrometry analysis of the epigenetic profile of $\mathrm{A} 549^{\triangle \mathrm{CHD}} 6$ relative to wild type revealed no significant changes in histone $\mathrm{H} 3$ or $\mathrm{H} 4$ acetylation or methylation marks linked to either open or compacted chromatin (Fig. 6c). However, when we assessed A549 $\triangle$ CHD6 chromatin sensitivity to limited micrococcal nuclease (MNase) digestion, which cleaves nucleosome linker DNA and is more active in relaxed chromatin ${ }^{9}, \mathrm{~A} 549^{\triangle \mathrm{CHD}} 6$ displayed increased MNase sensitivity (Fig. 6d), indicative of CHD6 promoting compaction at, overall, more genomic regions than it relaxes and providing a plausible explanation for the exaggerated ATM signaling and G2/M checkpoint sensitivity in these cells.

The increased MNase sensitivity and greater DNA damage signaling in A549 $\triangle \mathrm{CHD} 6$ is reminiscent of effects caused by perturbed histone $\mathrm{H} 1$ occupancy ${ }^{42,43}$ or depleting the CHD3 or KAP1 constitutive heterochromatin builders $9,10,41,44$. Histone H1 contributes to chromatin relaxation by being displaced via PAR and re-incorporated by an uncertain mechanism ${ }^{42,43,45}$. We found no difference in $\mathrm{H} 1$ displacement or reincorporation dynamics in A549 ${ }^{\Delta \mathrm{CHD} 6}$ cells compared to wild type (Supplementary Fig. 4c). Immunofluorescence analysis of euchromatin markers $\mathrm{H} 3{ }^{\mathrm{K} 4 \mathrm{me} 3}$ or $\mathrm{H} 4{ }^{\mathrm{K} 8 \mathrm{ac}}$ or constitutive heterochromatin markers $\mathrm{H}_{3}{ }^{\mathrm{K} 9 \mathrm{me} 3}$ and KAP1 confirmed no gross alterations in A549 $\triangle$ CHD6 (Supplementary Fig. 4e). We further examined this by assessing the ATM dependency of DSB repair, as cells with perturbed constitutive heterochromatin (e.g., via CHD3 depletion) show no need for ATM activity during repair (Fig. 6e) (9,10,44 $^{2}$ A549 ${ }^{\triangle \mathrm{CHD} 6}$ cells displayed normal ATM dependency, suggesting that $\mathrm{CHD} 3$-dependent heterochromatin is functionally independent of CHD6 status, at least in the context of the DNA damage response (Fig. 6e). Altogether, these data raise the possibility that CHD6 regulates chromatin compaction or accessibility in such a way that is apparently distinct to $\mathrm{CHD} 3$, but elicits a comparable increase in ATM signaling when absent ${ }^{9,10,36,39}$.

CHD6 loss leads to failure to thrive after oxidative stress. Finally, we performed survival and proliferation experiments after acute $\left(\mathrm{H}_{2} \mathrm{O}_{2}\right.$ in PBS for $20 \mathrm{~min}$, then removed) or chronic $\left(\mathrm{H}_{2} \mathrm{O}_{2}\right.$ added to media, refreshed daily) oxidative stress. Relative to controls, the clonogenic potential of A549 ${ }^{\Delta \mathrm{CHD}} 610$ days after acute $\mathrm{H}_{2} \mathrm{O}_{2}$ exposure trended downwards, although this lacked statistical significance (Fig. 7a). This result was clarified by cell growth analysis, which revealed that although A549 $\triangle \mathrm{CHD} 6$ cells undergo a significant attrition within $48 \mathrm{~h}$ of acute $\mathrm{H}_{2} \mathrm{O}_{2}$, they repopulate within 8 days (Fig. $7 \mathrm{~b}$ ). In contrast, wild-type controls only slowed growth after acute $\mathrm{H}_{2} \mathrm{O}_{2}$ and recover completely within 8 days (Fig. 7b). After chronic oxidative stress exposure, A549 $\triangle$ CHD6 clonogenic survival was reduced by 1-3 orders of magnitude in comparison to controls (Fig. 7c). Similarly, while wild-type cells were unaffected by chronic exposure to $5-50 \mu \mathrm{M}$ $\mathrm{H}_{2} \mathrm{O}_{2}$ and only experience growth stasis at $500 \mu \mathrm{M} \mathrm{H}_{2} \mathrm{O}_{2}$, the A549 ${ }^{\triangle \mathrm{CHD}} 6$ attenuated growth in $5 \mu \mathrm{M} \mathrm{H}_{2} \mathrm{O}_{2}$ and exhibited significant dose-dependent cell death in $50-500 \mu \mathrm{M} \mathrm{H}_{2} \mathrm{O}_{2}$ (Fig. 7d). Identical effects were seen when cells were grown at either $21 \%$ or $3 \%$ oxygen (Fig. 7 e vs. Supplementary Fig. $4 d$ ). We attempted to restore CHD6 expression and monitor cell growth; however, these experiments were precluded by cell death observed in CHD6overexpressing cells $>4$ days after transfection. We speculated this was due to the acrimonious long-term impact of an overexpressed chromatin remodeling enzyme potentially lacking stoichiometric levels of as yet unknown regulatory factors. In lieu, we expressed HMOX1 to address to what extent CHD6dependent antioxidant responses contribute to cell survival 
b

a

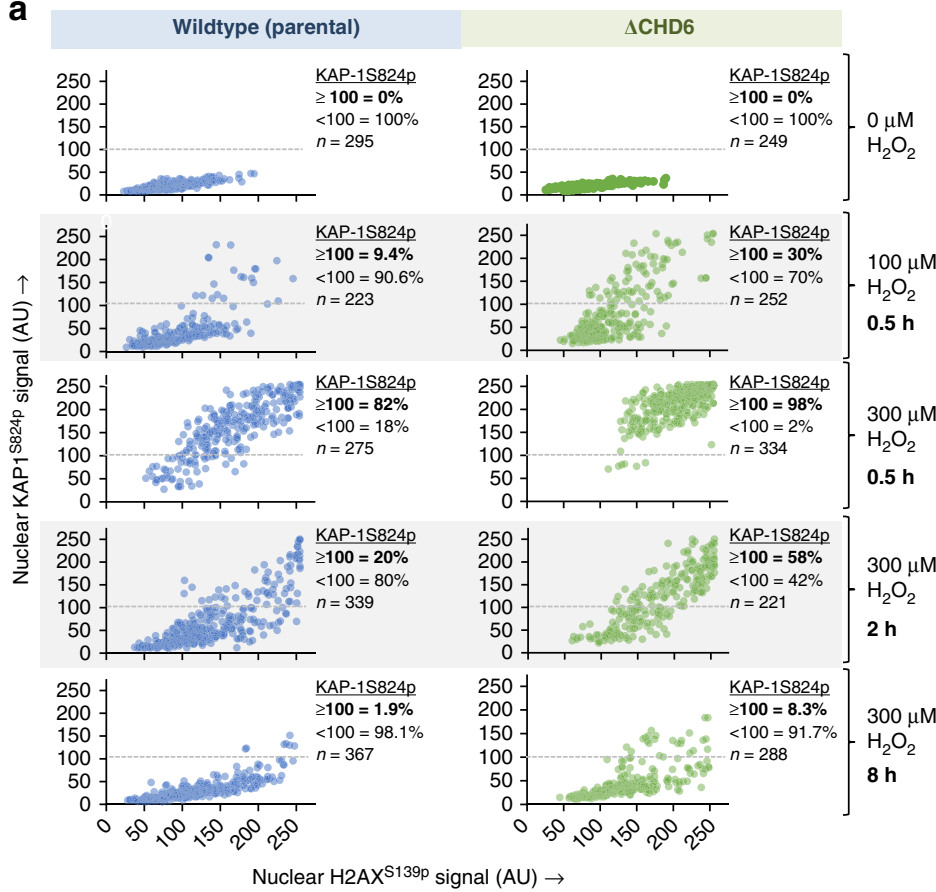

C

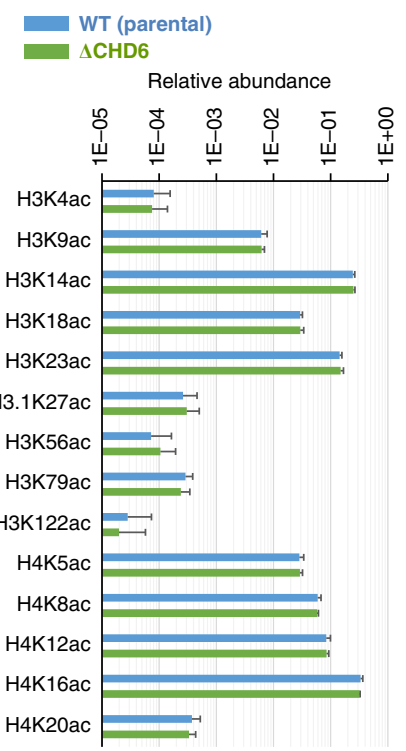

H3K18me

H3K23me

H3.1K27me 1

H3.1K27me2

H3.1K27me3

H3.1K36me 1

H3.1K36me2

H3.1K36me3

H3K $56 \mathrm{me}$

H3K56me2

H3K79me 1

H3K79me2

H3K79me3

H4K20me

H4K2Ome2

Relative abundance

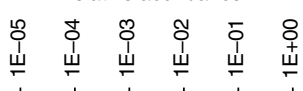

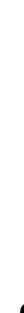

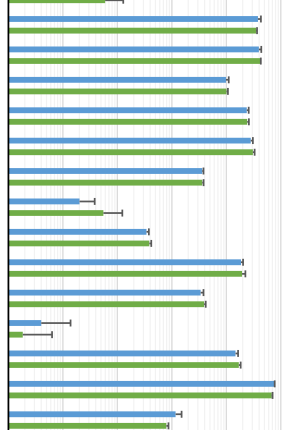

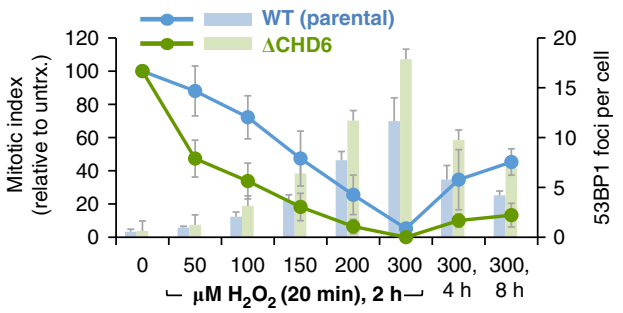

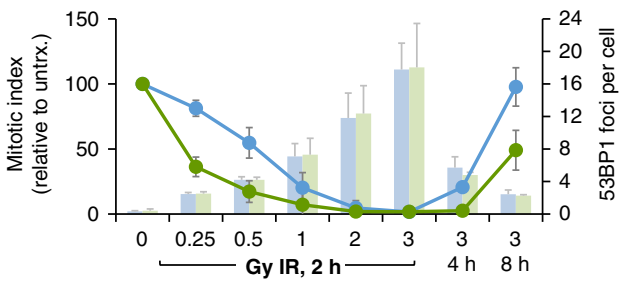

d
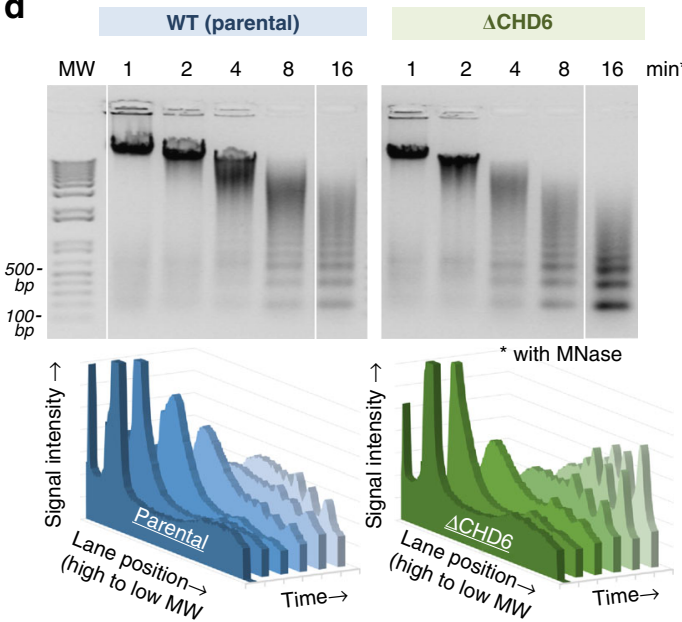

e

e 40 I I $\quad$ WT + DMSO

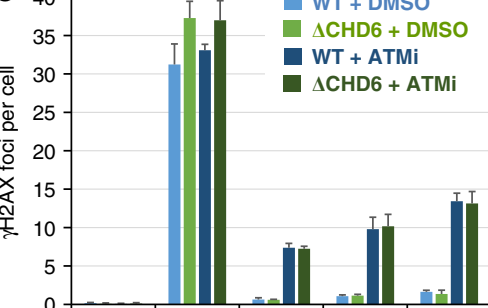

40 -

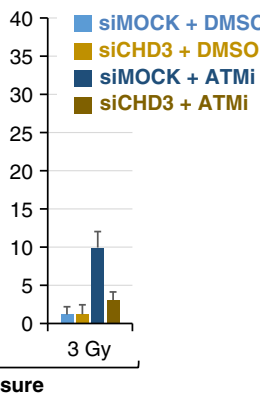

Fig. 6 CHD6-deficient cells have hypersensitive cell cycle checkpoint arrest, abnormally relaxed chromatin but functionally normal constitutive heterochromatin and epigenetics. a WT and A549 $\triangle \mathrm{CHD} 6$ were exposed to 0-300 $\mu \mathrm{M} \mathrm{H}_{2} \mathrm{O}_{2}$ in PBS for 20 min, washed, returned to media for 0.5-8 h, immunostained and quantified for nuclear KAP1 ${ }^{S 824 p}$ and $\mathrm{H}_{2} \mathrm{AX} \mathrm{X}^{\mathrm{S} 139 \mathrm{p}}$ signal (200-300 cells across $n$ of 3 ). Percentage cells with $\geq 0$ or $<100 \mathrm{KAP} 1^{\mathrm{S} 824 \mathrm{p}}$ signal (demarcating substantial DNA damage signaling) is indicated. Data represent $n=3$. b WT and A549 $\Delta \mathrm{CHD} 6$ were exposed either to $0-300 \mu M \mathrm{H}_{2} \mathrm{O}_{2}$ in PBS for 20 min, washed, returned to media for 2-8 h, or irradiated with 2 Gy IR before being fixed and immunostained for 53BP1 (demarcating DSBs), $\mathrm{DAPI}$ and $\mathrm{H}^{\mathrm{S} 10 \mathrm{p}}$ (to demarcate $\mathrm{G} 2 / \mathrm{M}$ phase cells). Mitotic indexes (lines, left $\mathrm{y}$-axis) were derived from the \% $\mathrm{M}$-phase cells (=strongly positive $\mathrm{H} 3^{\mathrm{S}}$ ) signal and DAPI morphology) relative to control. The 53BP1 foci per cell (bars, right $y$-axis) were also enumerated. Error bars $=$ s.e.m.; $n=3$. c $1 \times 10^{7}$ WT and $A 549^{\triangle C H D 6}$ were processed via acid extraction to isolate histones, which were then derivatized with propionic anhydride, digested and quantified for the indicated epigenetic modifications by mass spectrometry (see Methods). Error bars $=$ s.d.; $n=6$. $\mathbf{d}$ Nuclei isolated from confluent WT and A549 $\Delta \mathrm{CHD} 6$ were exposed to MNase for indicated times before isolation and resolution of genomic DNA by agarose gel. Representative ethidium bromide-stained 1.2\% agarose gels are shown (upper panels, inverted signal) alongside quantified DNA signal across each lane (lower panels) from a total of $n=3$. e WT and A549 $\triangle \mathrm{CHD} 6$ were transfected with scrambled, CHD6 or CHD3 siRNA $48 \mathrm{~h}$ before incubation with DMSO or $10 \mu \mathrm{M}$ ATMi 30 min prior to irradiation, fixation at indicated times, $\gamma \mathrm{H} 2 \mathrm{AX}$ immunostaining and foci enumeration. Error bars $=$ s.e.m.; $n=3$. In all cases, blue refers to WT cells; green refers to $\triangle$ CHD6 cells and yellow refers to WT cells treated with CHD3 siRNA 
a

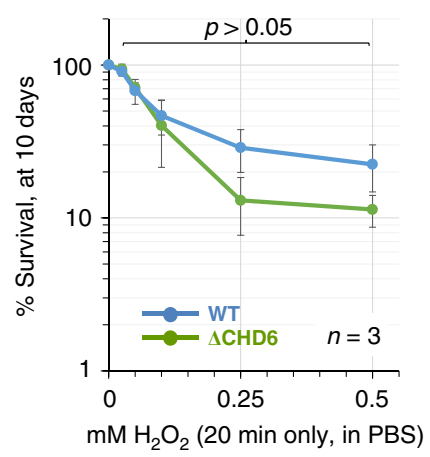

b

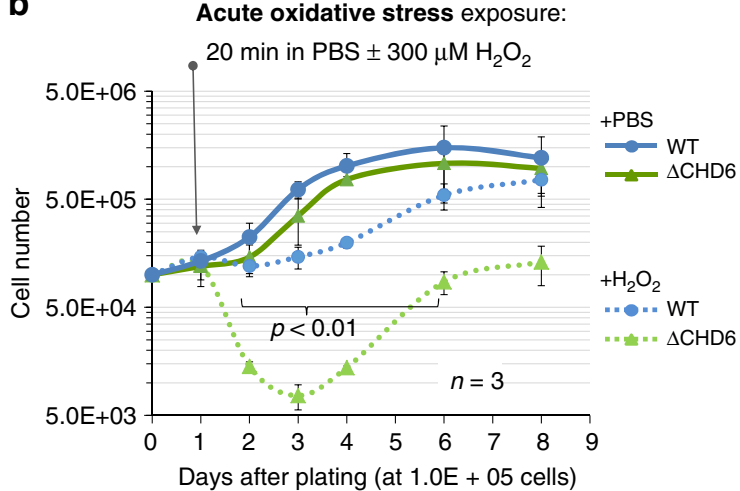

Chronic oxidative stress exposure

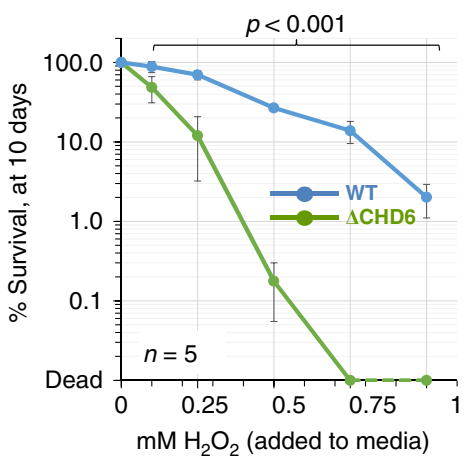

d

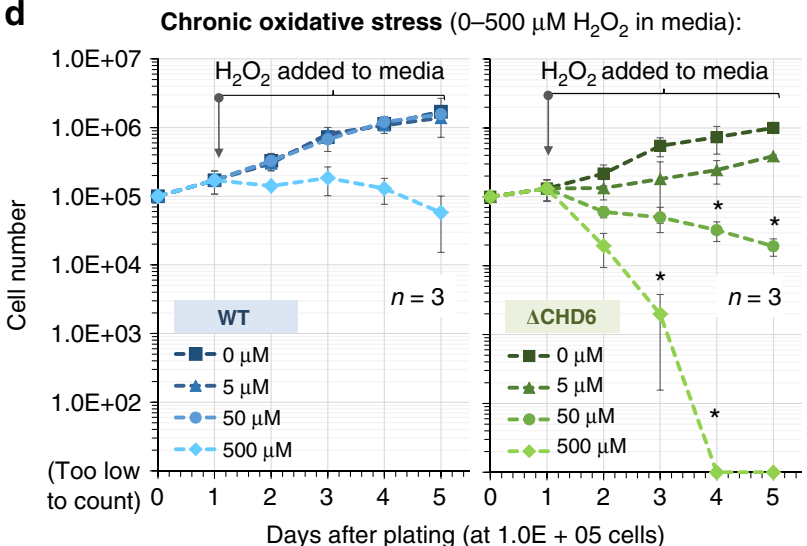

f

1. Reactive oxygen species induced DNA lesions \& strand breaks

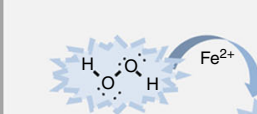

Fenton reaction

converting
$\mathrm{H}_{2} \mathrm{O}_{2}$ to $\mathrm{OH}^{\circ}$

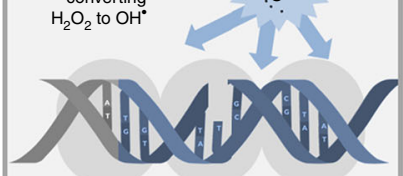

2. CHD6 stabilization and relocalization to PAR chains and oxidized DNA lesions

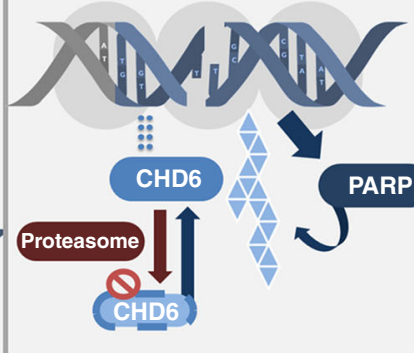

. Oxidative DNA damage and radicals trigger ATM signalling and checkpoint arrest that is impacted by..

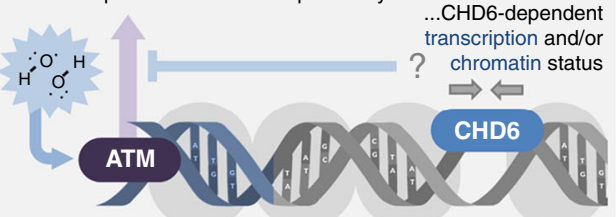

Transfected with HMOX $\mathbf{1}^{\text {GFP }}$
$\mathrm{H}_{2} \mathrm{O}_{2}$ added to media (chronic)

Split 2.0E +05 to dish Plasmid transfection
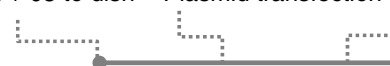

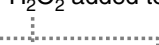

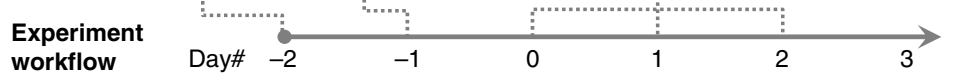

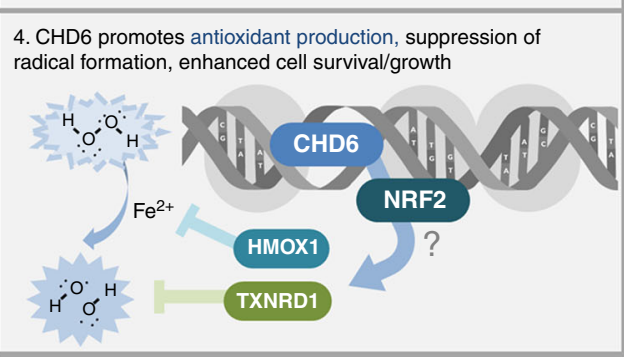

Fig. $7 \mathrm{CHD6}$ loss causes failure to thrive after oxidative stress and perturbed oxidative base excision repair initiation. a WT and A549 ${ }^{\Delta C H D 6}$ cells were exposed to $\mathrm{H}_{2} \mathrm{O}_{2}$ in PBS for 20 min, washed, plated and scored for colony formation 10 days later. Error bars = s.e.m.; $n=3 ; P$ value determined by two-way ANOVA. b The 1.0E +05 WT and A549 $\triangle \mathrm{CHD} 6$ were plated and, $24 \mathrm{~h}$ later, exposed to $\pm 300 \mu \mathrm{M} \mathrm{H}_{2} \mathrm{O}_{2}$ in PBS for 20 min, washed and returned to media for 8 days. Viable cells were counted daily. Error bars $=$ s.e.m.; $n=3$. $P$ values represent unpaired $t$-test between WT and A549 ${ }^{\Delta C H D 6}$ at indicated time points. c The 300 $\times$ WT and A549 $\triangle \mathrm{CHD} 6$ cells were exposed to $\mathrm{H}_{2} \mathrm{O}_{2}$ in media for $48 \mathrm{~h}$, plated and scored for colony formation 10 days later. Error bars $=$ s.e.m.; $n$ $=5 ; P$ value determined by two-way ANOVA. $\mathbf{d}$ The 1.0E $+05 \mathrm{WT}$ and $\mathrm{A} 549 \Delta \mathrm{CHD} 6$ were plated and, $24 \mathrm{~h}$ later, $0-500 \mu \mathrm{M} \mathrm{H} \mathrm{H}_{2} \mathrm{O}$ was added to media. Fresh $\mathrm{H}_{2} \mathrm{O}_{2}$ was added daily to maintain chronic exposure. Cells were analyzed as in (b). Error bars = s.e.m.; $n=3$. e WT and A549 $\mathrm{CHD6}$ were seeded at $2.0 \mathrm{E}+05$ and, $24 \mathrm{~h}$ later, transfected with either GFP or HMOX1GFP. After $24 \mathrm{~h}$, cells were exposed to $500 \mu_{M} \mathrm{H}_{2} \mathrm{O}_{2}$ in media and counted as in (d). For unpaired $t$-test at indicated points relative to $0 \mu \mathrm{M} \mathrm{H}_{2} \mathrm{O}_{2}$ control; ${ }^{*} p<0.05$. In all cases, \pm refers to with and without, blue refers to WT cells; green refers to $\triangle$ CHD6 cells. $\mathbf{f}$ A model for CHD6 function. (1) ROS such as hydroxyl radicals react with DNA to produce oxidative damage. (2) Oxidative stress suppresses proteasomal degradation of $\mathrm{CHD6}$, stabilizing protein levels, while oxidative DNA breaks elicit PARP enzyme activation, generating PAR polymers in the vicinity of DNA lesions that enable CHD6 relocalization to oxidative DNA lesions. (3) CHD6 contributes to nucleosome compaction and transcriptional responses, which potentially modulate the magnitude of ATM-dependent signaling. (4) CHD6 promotes oxidative stress transcriptional responses (potentially via Nrf2) and, as a consequence, antioxidant proteins such as HMOX1 and TXNRD1 suppress oxidative stress and DNA damage 
during oxidative stress. HMOX1GFP was well tolerated, and although growth slowed after GFP or HMOX1 ${ }^{\text {GFP }}$ transfection, minimal cell death was observed. As with naive cells, A549 $\triangle$ CHD6 expressing GFP experienced cell growth failure and death after chronic $\mathrm{H}_{2} \mathrm{O}_{2}$ exposure; by contrast, A549 ${ }^{\Delta \mathrm{CHD} 6}$ expressing HMOX $1{ }^{\mathrm{GFP}}$ were able to withstand oxidative stress to a similar extent as wild-type A549 transfected with either GFP or HMOX1GFP (Fig. 7e). Collectively, these data indicate a substantial deficit in the ability of CHD6 knockout cells to withstand oxidative stress, with CHD6-dependent oxidative stress responses being important for growth and survival following acute exposure and crucial in chronic stress scenarios.

\section{Discussion}

Endogenous and exogenous ROS generate thousands of oxidative lesions per cell on a daily basis. As oxidative genomic damage is mutagenic and potentially lethal, cells must repair injured DNA and/or evade damage induction to survive, function normally and proliferate. Our results indicate that CHD6 may be a primary oxidative DNA damage response factor (Fig. 7f), although at this point it is unclear whether it exerts its effects though (i) direct activity at DNA damage sites, (ii) chromatin compaction regulation, (iii) the antioxidant response transcriptional regulation or (iv) some combination of (i-iii). Our results with HMOX1 expression indicate that CHD6's role in antioxidant regulation is likely a major contributor to its impact on cell growth and survival. As such, CHD6 joins a growing list of chromatin remodelers that respond to DNA damage to promote recovery ${ }^{46}$. During oxidative stress, loss of CHD6 leads to elevated DNA break and PAR induction, increased ROS, reduced antioxidant production, abnormal chromatin status, greater ATM signaling, hypersensitive checkpoint activation and failure to grow and thrive. CHD6 is stabilized during oxidative stress, and relocates to oxidative DNA damage sites. CHD6 is distinguished from other CHD enzymes, such as CHD1, CHD2 and CHD4, in that it appears to have no direct role in the DNA repair pathways examined so far, does not bind non-oxidative DSBs and exacerbates oxidative stress when ablated. CHD6 is also distinct to CHD3 as, although deletion enhances ATM activation, it has little impact on the ATM dependency of DSB repair and is not ultimately lethal, indicative that CHD6 (unlike CHD3) ${ }^{10}$ is dispensable for constitutive heterochromatin building or inheritance through DNA replication. Nevertheless, like CHD3 depletion, loss of CHD6 enhances nuclease accessibility to chromatin, raising the possibility that it is either a key part of complexes that regulate linker histone DNA access or is a net chromatin compacter. This latter idea is consistent with evidence that CHD6 binds to human papillomavirus E8-E2C proteins and to repress the E6/E7 promoter $^{47}$.

As an alternative explanation to the chromatin hypothesis, it is quite possible that the enhanced ATM signaling seen in $\triangle \mathrm{CHD} 6$ cells is due to direct ATM activation via the formation of disulfide cross-linkage within ATM dimers driven by elevated ROS levels, even when DSBs are limiting or absent ${ }^{48}$, or via SSB-mediated activation as described previously ${ }^{49}$. A central question emerging from our work is how CHD6 can be involved in promoting antioxidant transcription as well as broadly suppressing chromatin accessibility? It is important to note that CHD6, like many chromatin remodeling enzymes, likely contributes to the compaction of some genomic loci, while relaxing others (reviewed in ref. ${ }^{1}$ ). To clarify this, an important next step will be mapping CHD6 chromatin occupancy across the human genome with and without oxidative stress, as well as identifying interacting partners conferring differential functional specificity. Important first steps in this were taken recently, in a study demonstrating that CHD6 tethers cis-acting CFTR (cystic fibrosis transmembrane conductance regulator) regulatory elements in proximity to a variety of transcriptional complexes important for cell differentiation ${ }^{50}$.

Our results suggest that CHD6 also contributes to ROS detoxification, a feasible explanation as to why, mechanistically, CHD6-ablated cells experience elevated oxidative DNA damage (and increased PAR) for a given dose of $\mathrm{H}_{2} \mathrm{O}_{2}$. We speculate that CHD6 loss leads to a failure to thrive in an oxidatively stressed environment due to the multiplying effects of reduced antioxidant capacity, greater DNA damage and PAR induction coupled with amplified signaling manifesting together as elevated ATM and checkpoint arrest and/or cell death. This may well explain the phenotype of cerebellar degeneration defects found in CHD6 $\Delta$ exon12 mice and, in the future, it will be informative to challenge such mice with ectopic oxidative stress to test whether degenerative phenotypes, DNA damage induction, NAD+ depletion (which is tied with steady-state PAR induction) and the related parthanatos cell death process are exacerbated ${ }^{51}$.

As we found for CHD6, CHD2 and CHD4 retention at DNA damage is PAR dependent. CHD2 recruitment is conferred by a C-terminal PAR-binding region ${ }^{3}$, while $\mathrm{CHD} 4$ reportedly interacts with PAR via an N-terminal HMG box-like domain ${ }^{7,52}$. Neither of the CHD2/4 PAR-binding regions are present in the CHD6 polypeptide; rather, we map the PAR-dependent binding region to a small area between the NLS and double chromodomain containing a conserved KR-rich patch. This area is required for the very rapid, early relocalization of CHD6 to sites of DNA damage, with the slower accumulation of the protein then requiring the double chromodomain and other central core domains. Answering whether CHD6 directly binds PAR, as well as elucidating the exact functional role of each central domain, will require this large protein (and mutants thereof) to be purified and biochemically interrogated. It will also be important to further elucidate what CHD6 does at sites of DNA damage as, although mutants defective in DNA damage retention (e.g., $\triangle \mathrm{CD} 1+2$ mutant) cannot complement the $\triangle \mathrm{CHD} 6$ phenotype, nucleosome (or other) substrates of CHD6 at oxidative DNA damage need to be identified.

Cancers experience increased proliferation and inflamed microenvironments leading to chronic oxidative stress, and must adapt to survive $e^{53}$. Our results fit with the idea that CHD6 promotes growth under adverse oxidative conditions, and might explain why cancers arising from often oxidatively stressed tissues (e.g., colorectal cancer) display CHD6 gene amplification (Supplementary Fig. 4f). Unlike other CHD enzymes known to respond to DNA damage induction, we find that CHD6 protein levels are regulated by a proteasome-mediated degradation process that responds to oxidative stress. This is reminiscent of p53 or Nrf2 upregulation under similar circumstances and, in those cases, ubiquitin-ligases (MDM2 and KEAP1, respectively) are switched off following stimuli to suppress ubiquitin-directed proteasome degradation; ${ }^{53}$ however, we have not been able to observe direct ubiquitylation of CHD6 using standard approaches. An alternative possibility is that oxidation of potentially important cysteine or methionine residues in CHD6 might underlie alterations to stability. Ascertaining whether constitutively increased CHD6 expression (in tumors) influences cancer patient survival will be important, as this may consolidate CHD6 as a novel prognostic biomarker or anti-cancer target.

In conclusion, we suggest that CHD6 represents a central player in the oxidative DNA damage response, promoting antioxidant expression and chromatin compaction that, collectively, modulate DNA damage induction and persistence, DNA damage signal transduction and cell cycle checkpoint sensitivity to facilitate cell growth and survival under conditions of acute or chronic oxidative stress. 


\section{Methods}

Reagents and tissue culture. Phenylmethylsulfonyl fluoride (PMSF), Biotin, Wortmannin (WM), Microcystin-LR (MC-LR), $N$-ethylmaleimide (NEM), dithiothreitol (DTT), 3-aminobenzamide (3- $\mathrm{AB}), \mathrm{H}_{2} \mathrm{O}_{2}$ and streptavidin-agarose were all from Sigma. From Selleck Chemicals we obtained: PARPi AZD2281/ Olaparib, used at $2.5 \mu \mathrm{M}$; DNA-PKc inhibitor (DPKi) NU7441 (KU57788), used at $10 \mu \mathrm{M}$; and bortezomib (BTZ), used at $100 \mathrm{nM}$. From Tocris we obtained: PARGi PDD00017273, used as indicated, and ATM inhibitor (ATMi) KU-55933, used at $10 \mu \mathrm{M} . \mathrm{IR}=$ gamma rays $\left({ }^{137} \mathrm{Cs}\right)$ was delivered by GammaCell 1000 Elite (MDS Nordion). A549 (ATCC CCL-185) and HEK293 (ATCC CRL-1573) were cultured in Dulbecco's modified Eagle's medium (DMEM) with 10\% (v/v) fetal calf serum (FCS), GlutaMAX (Gibco), penicillin and streptomycin. U2OS-2-6-3 cells obtained from Dr. Susan Janicki (Wistar Institute, USA) are described in ref. ${ }^{54}$ and were also cultured in DMEM (as above). U2OS 2-6-3 cells stably expressing ERmCherry-LacR-FokI-DD obtained from Dr. Roger Greenberg are described in ref. ${ }^{26}$ were induced for $5 \mathrm{~h}$ by $1 \mu \mathrm{M}$ Shield-1 (Clontech) and $1 \mu \mathrm{M} 4$-OHT (Sigma). U2OS XRCC1 ${ }^{-1-}$ cells were obtained from Dr. Keith Caldecott (University of Sussex, UK) and were also cultured in DMEM (as above). All cell lines are tested regularly for mycoplasma contamination and confirmed to be negative. A549 cell identity was confirmed by gene sequencing and karyotyping.

Immunoblotting (IB) and immunoprecipitation (IP) . For IB or IP, cells were lysed in $5 \times$ packed cell volume of ice-cold NETN buffer $(150 \mathrm{mM} \mathrm{NaCl}, 0.2 \mathrm{mM}$ EDTA, $50 \mathrm{mM}$ Tris- $\mathrm{HCl} \mathrm{pH} 7.5$ and $1 \%$ (v/v) NP-40 detergent) supplemented with $1 \times$ protease inhibitor cocktail (Roche), $1 \mathrm{mM}$ DTT, PMSF, $1 \mu \mathrm{M}$ WM, $10 \mathrm{mM}$ NEM, $5 \mu \mathrm{M}$ PARGi, 3-AB, and $0.1 \mu \mathrm{M}$ MC-LR and sonicated $(10 \%, 5 \mathrm{~s})$ and clarified at 10,000 rpm for $10 \mathrm{~min}$. For GFP IP examining interactions with PAR, 2 $\mathrm{mg}$ of lysate was incubated with $5 \mu \mathrm{L}$ packed, equilibrated GFP Trap beads (Chromotek) for $2 \mathrm{~h}$ at $4{ }^{\circ} \mathrm{C}$ with rotation. For streptavidin-agarose pulldowns, beads were incubated in $50 \mu \mathrm{L} 1 \times$ phosphate-buffered saline (PBS) containing either $10 \mu \mathrm{M}$ free biotin, $10 \mu \mathrm{M}$ PAR-biotin (Trevigen) or $10 \mu \mathrm{M}$ H3K9me3-biotin (Epicypher) for $0.5 \mathrm{~h}$ at $4{ }^{\circ} \mathrm{C}$, with rotation, before being quenched by incubation with $500 \mu \mathrm{L}$ of $1 \mathrm{mM}$ TRIS $\mathrm{pH} 8.8$ containing $80 \mu \mathrm{M}$ free biotin for $15 \mathrm{~min}$ at $4{ }^{\circ} \mathrm{C}$, with rotation, and washed $2 \times$ with $1 \mathrm{~mL}$ NETN buffer. Then, $2 \mathrm{mg}$ lysate was incubated with $5 \mu \mathrm{L}$ packed beads for $2 \mathrm{~h}$ at $4{ }^{\circ} \mathrm{C}$, with rotation. After incubation, all IP pulldowns were washed up to $5 \times$ with $0.3 \mathrm{~mL}$ NETN. For IB, washed IPs or $25-$ $50 \mathrm{\mu g}$ lysates (inputs) were incubated at $95^{\circ} \mathrm{C}$ for $5 \mathrm{~min}$ in $1 \times$ Laemmli SDS Sample buffer and resolved by sodium dodecyl sulfate-polyacrylamide gel electrophoresis (SDS-PAGE). Secondary antibodies for IB were anti-mouse/rabbit/goat-HRP from Sigma. Immunolots were visualized by chemiluminescence and either film (Figs. 1a, e-g, 4a) or digital imaging (all other images) using a ChemiDoc (BioRad). Full size, uncropped scans or digital images of immunoblots are available in Supplementary Figs. 5-7.

Antibodies and immunofluorescence (IF). The primary antibodies from this study are indicated in Supplementary Table 2, along with the dilutions used. All secondary antibodies for IF were anti-mouse or anti-rabbit IgG coupled to Alexafluor 488 or 594 (Invitrogen Molecular probes; used at 1:800). For widefield microscopy IF, PBS-washed cells were fixed in 3\% (w/v) paraformaldehyde (PFA) $+2 \%(\mathrm{w} / \mathrm{v})$ sucrose for $10 \mathrm{~min}$, permeabilized for $3 \mathrm{~min}$ in $0.2 \%(\mathrm{v} / \mathrm{v})$ Triton X-100 (in PBS) and immunostained for $1 \mathrm{~h}$ with primary antibody (diluted in $2 \%(\mathrm{w} / \mathrm{v})$ BSA in PBS) for 30 min with 1:200 dilutions of secondary antibodies (also in $2 \%$ BSA as before). Where indicated, cells were counterstained with $0.1 \mu \mathrm{g} / \mathrm{mL} 4^{\prime}, 6-$ diamidino-2-phenylindole (DAPI) to visualized nuclei and were mounted using Polymount G. Samples were imaged with a Zeiss Axio Observer Z1 platform microscope, with a Plan Apochromat 20×/0.8, an EC Plan Neofluar $40 \times / 0.75$ or a Plan-Apochromatin 63×/1.4 (oil immersion) objective and an AxioCam MRm Rev.3 camera. Acquisition and analysis software used was Zen Pro (Zeiss). For confocal imaging, cells were fixed in $3 \%(\mathrm{w} / \mathrm{v}) \mathrm{PFA}+2 \%(\mathrm{w} / \mathrm{v})$ sucrose for $10 \mathrm{~min}$, permeabilized for $5 \mathrm{~min}$ in $0.5 \%(\mathrm{v} / \mathrm{v})$ Triton X-100 (in PBS), and immunostained for $1 \mathrm{~h}$ at room temperature (RT) with primary antibody (diluted in $2 \%(\mathrm{w} / \mathrm{v})$ BSA in PBS). For staining endogenous CHD6, primary antibody staining was carried out at $37^{\circ} \mathrm{C}$ for $30 \mathrm{~min}$ with $1: 400$ dilutions of secondary antibodies (also in $2 \%(\mathrm{w} /$ v) BSA as before). Cells were counterstained with $0.1 \mu \mathrm{g} / \mathrm{mL}$ DAPI to visualize nuclei and were mounted using Fluoromount G (Electron Microscopy Sciences). Samples were imaged with LSM880 Carl Zeiss confocal microscope, with a Plan Apochromat $20 \times / 0.8 \mathrm{NA}$, an EC Plan Neofluar $40 \times / 0.75 \mathrm{NA}$ or a Plan Apochromat $63 \times / 1.4 \mathrm{NA}$ (oil immersion) objective and a camera (AxioCam MRm Rev.3; Carl Zeiss) or GaAsP or Airyscan detectors (Carl Zeiss). Acquisition and analysis software used was Zen Blue and Zen Black (Carl Zeiss).

G2/M cell cycle checkpoint IF analysis. G2/M cell cycle checkpoint IF analysis was carried out exactly as in ref. ${ }^{41}$. Briefly, logarithmically dividing parental and A549 ${ }^{\Delta \mathrm{CHD} 6}$ cells grown on glass coverslips coated with $0.1 \%(\mathrm{w} / \mathrm{v})$ gelatin were treated (as indicated) and, at indicated time points, were fixed and immunostained (as outlined above) for H3S10p, 53BP1 and DAPI. Cells were imaged under 10x magnification for H3S10p and DAPI signal, and both total number and strongly H3S10p-positive cells with nuclear morphology indicative of mitosis were scored for $1200-5500$ cells per experimental repeat, with at least $4-6 \%$ of overall cell population being mitotic in the untreated condition.

\section{The $\mathbf{3 5 5} \mathbf{~ n m ~ l a s e r ~ m i c r o - i r r a d i a t i o n ~ a n d ~ l i v e ~ c e l l ~ i m a g i n g . ~ A 5 4 9 ~ c e l l s ~ w e r e ~}$} transfected with $2 \mu \mathrm{g}$ CHD6 expression construct (as indicated) $16 \mathrm{~h}$ before being incubated with $10 \mu \mathrm{M}$ BrdU (from Sigma) for 16-24 h. Small molecule inhibitors were all added to cells $1 \mathrm{~h}$ prior to DNA damage induction. DNA damage tracks were induced in live cells (kept at $37^{\circ} \mathrm{C}$ in a humidified environment at $5 \% \mathrm{CO}_{2}$ ) using a $355 \mathrm{~nm} 5 \mathrm{~mW}$ self-aligning solid state diode laser $(15 \mu \mathrm{m} / \mathrm{s}, 30 \%$ power) projected through a EC Plan-Neofluor 40× objective, via a Zeiss PALM MicroBeam laser microdissection module on a Zeiss Axio Observer Z1 platform. Images were captured on an AxioCam MRm Rev.3 camera. Laser irradiation was controlled by RoboSoftware 4.5. Acquisition and analysis software used was Zen Pro (Zeiss). CZI image files were captured every $60 \mathrm{~s}$ for the indicated times, and subsequently analyzed using Zen image processing software. For analysis of signal gain, a region of interest was created to cover the area of the laser track and the signal intensity (arbitrary units) within this area was measured over the time course. To measure cell background, a region of interest was cloned and placed next to the region containing the track, providing the signal intensity for background of an area of identical size within the nuclei. The signal intensity of background is then subtracted from the signal intensity of the track, divided by the sum of both regions of interest and presented as a percent gain in signal intensity with the pre-damage $(t$ $=0$ ) representing baseline.

Site-specific Fok1 and KillerRed DNA damage system. U2OS 2-6-3 cells stably expressing ER-Fok1-mCherry-LacR-DD (estrogen receptor (ER), destabilization domain (DD) $)^{26}$ (obtained from Dr. Roger Greenberg, University of Pennsylvania, USA) were induced with $300 \mathrm{nM} \mathrm{4-OHT}$ and $1 \mu \mathrm{M}$ Shield-I for $5 \mathrm{~h}$. Subsequently, cells were pre-extracted using $0.25 \%(\mathrm{v} / \mathrm{v})$ Triton X-100 in cytoskeletal (CSK) buffer (10 mM HEPES pH 7.4, $300 \mathrm{mM}$ Sucrose, $100 \mathrm{mM} \mathrm{NaCl}$, and $3 \mathrm{mM} \mathrm{MgCl}$ ) for $10 \mathrm{~min}$, fixed with formaldehyde and immunostained with the indicated antibodies. KillerRed cDNA (obtained from Dr. Joachim Goedhart, University of Amsterdam, The Netherlands) was amplified by PCR using the primers: 5TCAGCTAGCGTGTACGGTGGGAGGTCTA-3 and 5-AGTTGTACACATCCTCGTCGCTACCGATG-3, and inserted into mCherry-LacR-stop using NheI and BsrGI to generate KillerRed-LacR-stop. U2OS 2-6-3 cells were cotransfected with $1.5 \mu \mathrm{g}$ KillerRed-LacR-stop and $1 \mu \mathrm{g}$ GFP-CHD6 or GFP-XRCC1 Immediately after transfection, dishes containing cells were wrapped in aluminum foil to prevent KillerRed activation. The induction of ROS by activation of KillerRed was done essentially as described previousl $y^{55}$. Briefly, $24 \mathrm{~h}$ after transfection, cells were exposed to a $24 \mathrm{~W}$ Osram dulux white fluorescent bulb for $375 \mathrm{~s}$ in a customized stage $15 \mathrm{~cm}$ away from the light bulb. The $375 \mathrm{~s}$ exposure to light at a rate of $24 \mathrm{~W}(=24 \mathrm{~J} / \mathrm{s})$ results in dose of $9000 \mathrm{~J}$. Alternatively, cells were exposed for $188 \mathrm{~s}$ (4500 J) or $94 \mathrm{~s}(2250 \mathrm{~J})$ when indicated. After exposure, cells were immediately fixed for 20 min with $4 \%$ formaldehyde. In parallel to KR activation, cells were treated with $5 \mu \mathrm{M}$ PARGi for $30 \mathrm{~min}$ and subsequently exposed to varying concentrations of $\mathrm{H}_{2} \mathrm{O}_{2}(0.1,0.5$ or $1.0 \mathrm{mM})$ for $1 \mathrm{~h}$ in DMEM $+10 \%$ FCS to compare $\mathrm{H}_{2} \mathrm{O}_{2}$-induced and KR-induced PAR, $\gamma \mathrm{H} 2 \mathrm{AX}$ or XRCC4 recruitment.

Plasmids, siRNA and transfection. The GFP-tagged CHD4 construct is described in ref. ${ }^{3}$. GFP-C3-PARP1 was a gift from Valerie Schreiber as described in ref. ${ }^{56}$. GFP-tagged XRCC1 was obtained from Keith Caldecott (University of Sussex, UK) The GFP-tagged HMOX1 plasmid (pCX-HO1-2A-EGFP) was a gift from Roberto Giovannoni (Addgene plasmid \# 74672) ${ }^{57}$. CHD6 expression constructs (CHD6 ${ }^{\mathrm{GFP}}$, $\mathrm{CHD6}^{\mathrm{FLAG}}, \mathrm{CHD6}{ }^{\mathrm{mPLUM}}$ ) were made by cloning in full-length wildtype human CHD6 cDNA (accession NM_032221; NP_115597) into either a pEGFP-C2 backbone, pCMV6-Entry-FLAG or mPlum-C1 (a gift from Michael Davidson (Addgene plasmid \# 54839) ${ }^{58}$ ) backbone, all under cytomegalovirus (CMV) promoters (Clonetech). Where indicated, GFP alone refers to empty pEGFP-C2 vector. Plasmid transfection was achieved using PolyPlus (VWR) according to the manufacturer's protocol. siRNA-mediated knockdown was also achieved with PolyPlus transfection using 100 pmol of siRNA duplexes per $2 \times 10^{5}$ cells. The siRNA to CHD2 and Ku80 (and scrambled controls) used in Fig. 5g were as described in ref. ${ }^{3}$. Other siRNAs were Stealth ${ }^{\text {tw }}$ siRNA oligos from Invitrogen used as a 1:1 pool of A+B sequences as indicated in Supplementary Table 3. GFPtagged CHD6 plasmid mutations (including amino acid changes, nucleotide positions and changes) are indicated in Supplementary Table 4.

Quantitative PCR. Cell pellets were lysed with Trizol reagent (Ambion) to extract RNA. cDNA was synthesized with $1 \mu \mathrm{g} / \mu \mathrm{L}$ of RNA using Superscript II reverse transcriptase (Invitrogen). qPCR analysis was performed using SYBR green (Life Technologies) to determine Nrf2 target mRNA expression. Conditions were loaded in triplicate and for analysis, the CT values from each repeat were averaged. The averaged CT values for each condition were normalized to the respective GAPDH for loading control to obtain the $\Delta \mathrm{CT}$ value. To obtain the $\Delta \Delta \mathrm{CT}$, the values for each treated condition was normalized to the parental NT. The $\Delta \Delta$ CT values were then expressed as fold change in expression relative to NT averaged over three independent repeats. Primers sequences are indicated in Supplementary Table 5. 
CRISPR-based gene editing. CRISPR guide sequences targeting CHD6 exon 3 were designed using the online CRISPR design tool at (crispr.mit.edu): CHD6 sgRNA: AA ACGTATACTGCTGAAGAGGAAGC. Guide sequences were integrated into the pXPR_001 plasmid containing Cas ${ }^{59}$. Constructs were transfected into parental A549 cells and subjected to puromycin $(1 \mathrm{mg} / \mathrm{mL})$ selection for 7 days. After this, polyclonal cells were assayed for CHD6 expression and subjected to single cell cloning by serial dilution. Single cell clones were screened by immunoblotting and clones positive for loss of CHD6 expression were identified, expanded and confirmed by PCR analysis using primers adjacent to the CHD6 sgRNA sequence: CHD6 exon3, forward: 5'-GGAATTCCACTCCCCAATGTCTGATGC-3'; CHD6 exon3, reverse: 5'-CGGGATCCTTGTGCTCCTTGGCCTTCTT-3'. DNA sequencing confirmed that both alleles of CHD6 in the parental A549 line conformed to the GenBank wild-type CHD6 nucleotide (nt) sequence, while multiple (eight) independent runs indicated that $100 \mathrm{nt}$ were deleted in both alleles of the $\triangle \mathrm{CHD} 6$ A549 line, specifically nt 186-285 (corresponding to amino acids 63-95) of the third exon, with the remainder of the gene sequence conforming to wild type.

Micrococcal nuclease (MNase) chromatin relaxation assay. Performed exactly as in Klement et al. ${ }^{10}$. Briefly, nuclei were isolated from confluent cultures of parental and $\triangle$ CHD6 A549 cells. For MNase (Nuclease S7, from Roche) digestion, $75 \mu \mathrm{L}$ nuclei was used per time point, with the addition of $1 \mathrm{U} / \mu \mathrm{L}$ MNase and incubation at $25^{\circ} \mathrm{C}$ for indicated times. Then, $75 \mu \mathrm{L}$ reactions were quenched with the addition of $1.5 \mu \mathrm{L} 0.5 \mathrm{M}$ EDTA. Protein was digested with $1 \mathrm{mg} / \mathrm{mL}$ Proteinase $\mathrm{K}$ (Sigma) in $5 \%(\mathrm{w} / \mathrm{v}) \mathrm{SDS}$ for $30 \mathrm{~min}$ at $37^{\circ} \mathrm{C}$, extracted with phenol/chloroform, washed with diethyl ether and DNA precipitated with the addition of ethanol to $75 \%$ and incubation overnight at $-20^{\circ} \mathrm{C}$. Then, $2.5 \mu \mathrm{g}$ of rehydrated DNA was resolved on a $1.2 \%(\mathrm{w} / \mathrm{v})$ agarose gel run in $1 \times \mathrm{TAE}$ buffer.

Clonogenic survival analysis. For acute $\mathrm{H}_{2} \mathrm{O}_{2}$ exposure, 300 cells were seeded in duplicate into $6 \mathrm{~cm}$ dishes and allowed to attach for $8 \mathrm{~h}$. Media were then removed, cells were washed with $1 \times$ PBS and exposed to $\mathrm{H}_{2} \mathrm{O}_{2}$ in ice-cold $1 \times$ PBS at RT before being rinsed in $1 \times$ PBS and placed back into conditioned media. For chronic $\mathrm{H}_{2} \mathrm{O}_{2}$ exposure, confluent cells were exposed to $\mathrm{H}_{2} \mathrm{O}_{2}$ in media for $48 \mathrm{~h}$, with fresh $\mathrm{H}_{2} \mathrm{O}_{2}$ added daily before being split and 300 cells seeded into $6 \mathrm{~cm}$ dishes containing media with more $\mathrm{H}_{2} \mathrm{O}_{2}$. In all cases, cells were fixed 10 days later in $3 \%$ (v/ v) acetic acid, $8 \%(\mathrm{v} / \mathrm{v})$ methanol and stained with crystal violet $(0.2 \%(\mathrm{w} / \mathrm{v})$ crystal violet, $4 \%(\mathrm{w} / \mathrm{v})$ PFA in PBS). Colonies were counted expressed as a percentage of untreated.

Alkaline comet assay. The day before, $0.8 \%(\mathrm{w} / \mathrm{v})$ in PBS agarose (Invitrogen) plugs were prepared on frosted slides (VWR). The lysis buffer $(5 \mathrm{M} \mathrm{NaCl}, 0.5 \mathrm{M}$ EDTA, $1 \mathrm{M}$ Tris $\mathrm{pH} 10 ; \mathrm{pH} 10$ with $5 \mathrm{M} \mathrm{NaOH})$ and electrophoresis buffer $(10 \mathrm{M}$ $\mathrm{NaOH}, 0.5 \mathrm{M}$ EDTA) were also prepared the day before. Parental and $\triangle \mathrm{CHD} 6$ A549 cells were collected, washed once with $1 \times$ PBS, counted and diluted to $2 \times 10^{5}$ per $\mathrm{mL}$. Then, cells were resuspended in PBS containing the indicated dose of $\mathrm{H}_{2} \mathrm{O}_{2}$, returned to the incubator and $1 \mathrm{~mL}$ of cells was removed per time point. After treatment, cells were washed $2 \times$ with $1 \times$ PBS and the pellet collected and resuspended in $1 \mathrm{~mL}$ of PBS. For IR treatment, the cells are resuspended in cell media, irradiated with indicated dose, returned to the incubator and $1 \mathrm{~mL}$ of cells removed per time point. Cells were washed and prepared as above. Using $1.2 \%(\mathrm{w} /$ v) low-melting agarose (Invitrogen) in $1 \times$ PBS, $200 \mu \mathrm{L}$ of cells were placed in a fresh tube to which $200 \mu \mathrm{L}$ of warm low-melting agarose was added, mixed and $200 \mu \mathrm{L}$ was quickly pipetted on top of pre-set agarose plugs under a cover-slip. The plugs containing cells were left in the dark at $4^{\circ} \mathrm{C}$ to set for $30 \mathrm{~min}$. For lysis, coverslips were removed and slides placed in a black container in a dark cold room and incubated in lysis buffer (supplemented with $1 \%(\mathrm{v} / \mathrm{v})$ DMSO and $1 \%(\mathrm{v} / \mathrm{v})$ Triton X-100) for $1 \mathrm{~h}$. Cells were washed $3 \times$ in cold $\mathrm{dH}_{2} \mathrm{O}$ then slides placed in an electrophoresis chamber and covered in electrophoresis buffer (supplemented with $1 \%(\mathrm{v} / \mathrm{v})$ DMSO) for $45 \mathrm{~min}$ in the dark to neutralize $\mathrm{pH}$. Electrophoresis was carried out at $25 \mathrm{~V}$ for $25 \mathrm{~min}$, comets neutralized by submerging plugs in $0.4 \mathrm{M}$ Tris pH 7.0 until ready to score. Immediately prior to scoring, slides were stained with 1:10,000 dilution of SYBR green supplemented with $4 \mu \mathrm{g} / \mu \mathrm{L}$ of antifade (stock at $11 \mu \mathrm{g} / \mu \mathrm{L}$ ) for $5-10 \mathrm{~min}$ at RT in dark, removed and scored immediately. Comet scoring was performed on a Zeiss Axiovision microscope with a camera associated with Comet Assay IV software (Perspective Instruments). A total of 100 comets were scored per condition, per repeat the data expressed as the average comet tail moment on a scatter plot.

Cell growth analysis. Exactly $1 \mathrm{E}+05$ cells were seeded in $3 \mathrm{~cm}$ dishes, and allowed to recover for $24 \mathrm{~h}$. For acute $\mathrm{H}_{2} \mathrm{O}_{2}$ exposure, media were then removed, cells were washed with $1 \times$ PBS and exposed to $\mathrm{H}_{2} \mathrm{O}_{2}$ in ice-cold $1 \times$ PBS at RT before being rinsed in $1 \times$ PBS and placed back into conditioned media. For chronic $\mathrm{H}_{2} \mathrm{O}_{2}$ exposure, cells were exposed to $\mathrm{H}_{2} \mathrm{O}_{2}$ in media, with fresh $\mathrm{H}_{2} \mathrm{O}_{2}$ added daily for the duration of the experiment. Each day, cells were rinsed in $1 \times \mathrm{PBS}$, resuspended using trypsin-EDTA and viable cells were enumerated using a Moxi-Z cell counter.
Oxidative stress assay. $\mathrm{H}_{2}$ DCFDA (Thermo Fisher, D399) was prepared as a stock of $20 \mathrm{mM}$ in DMSO. Conditioned media were removed from cells and stored at $37^{\circ} \mathrm{C}$; cells were washed in $1 \times$ PBS and placed into phenol red and serum free media (DMEM, from Gibco) containing $20 \mu \mathrm{M} \mathrm{H}_{2}$ DCFDA for $1 \mathrm{~h}$ at $37^{\circ} \mathrm{C}$. Cells were then washed in $1 \times$ PBS and returned to conditioned media $\pm 500 \mu \mathrm{M} \mathrm{H}_{2} \mathrm{O}_{2}$ for $20 \mathrm{~min}$. Cells were then harvested by scraping into ice-cold PBS, washed once with $1 \times \mathrm{PBS}+0.0025 \%$ (w/v) Trypan blue to quench extracellular $\mathrm{H}_{2}$ DCFDA. 1E +06 cells were then subject to FACS analysis (University of Calgary FACS facility). For addback experiments, $\mathrm{A} 549^{\triangle \mathrm{CHD} 6}$ cells were transfected with $4 \mu \mathrm{g}$ of the CHD6-mPlum expressing construct $24 \mathrm{~h}$ prior to $\mathrm{H}_{2} \mathrm{O}_{2}$ exposure. For analysis, percent of P3-positive FITC cells was used as an indication of DCF intensity. For delta cells complemented with CHD6-mPlum, FITC-positive cells were quantified as a subset of mPlum expressing cells. The gating strategy applied for this experiment is indicated in Supplementary Fig. 8a.

Multiplexed DNA repair assays. FM-HCR assays were carried out in A549 and A549 ${ }^{\Delta \mathrm{CHD} 6}$ cells, as previously reported ${ }^{37,38}$. A549 and A549 ${ }^{\Delta \mathrm{CHD} 6}$ were maintained in culture under ambient culture conditions $\left(37^{\circ} \mathrm{C} / 5 \% \mathrm{CO}_{2}\right)$. Cells were seeded 2 days prior to harvesting for transfection (cells were harvested for transfection at $\sim 85 \%$ confluency). Ambient culture conditions for FM-HCR plasmid assays were compared to low oxygen culture $\left(37^{\circ} \mathrm{C} / 3 \% \mathrm{O}_{2}\right)$. For $3 \%$ oxygen culture, A549 and A549 4 CHD6 cells were equilibrated at $3 \% \mathrm{O}_{2}$ for $4 \mathrm{~h}$ and collected at the same time of ambient cell harvesting. A Neon Transfection System (Thermo Fisher Scientific) was used to transfect 500,000 cells using a $10 \mu \mathrm{L}$ tip two $1200 \mathrm{~V} 30 \mathrm{~ms}$ pulses. Cells were transfected with reporter plasmids with DNA lesions or corresponding undamaged reporter plasmids (see Supplementary Table 6) ${ }^{60}$. After transfection, A549 and A549 ${ }^{\Delta C H D 6}$ cells were seeded into 12 -well plates containing $2 \mathrm{~mL}$ of media per well, and were placed into either ambient or $3 \% \mathrm{O}_{2}$ culture conditions. At $24 \mathrm{~h}$ post transfection, cells were harvested and analyzed for DNA Repair Capacity (DRC) by flow cytometry. Fluorescent protein signal was quantitated for each respective plasmid for 15,000 cellular events per replicate $(n=3)$ Percent reporter expression for fluorescent proteins was quantified as previously described ${ }^{36,37}$. The gating strategy applied for this experiment is indicated in Supplementary Fig. 8b.

Mass spectrometry analysis of histones. Parental or delta CHD6 cells, $1 \times 10^{7}$ cells were collected and lysed in hypotonic lysis buffer prior to acid extraction of histones with $0.4 \mathrm{~N} \mathrm{H}_{2} \mathrm{SO} 4$ based on a previously descried protocol ${ }^{61}$. Histone concentration was determined by running histone solution (dissolved in $\mathrm{dH}_{2} \mathrm{O}$ ) on an SDS-PAGE gel and staining with Coomassie Brilliant Blue. Histone purification and analysis was performed as previously described, with minor modifications ${ }^{62}$. Briefly, histones were isolated using acid extraction and the trichloroacetic acid (TCA)-precipitated histones were resuspended in $\mathrm{ddH}_{2} \mathrm{O}$. Purity was confirmed by SDS-PAGE. The $\mathrm{pH}$ was adjusted to 8.0 by the addition of $\mathrm{NH}_{4} \mathrm{HCO}_{3}$ to a final concentration of $50 \mathrm{mM}$. Subsequent derivatization and digestion was performed in two independent replicates for each cell line. Histones were propionylated in two rounds exactly as described previously ${ }^{63}$ and subsequently digested with trypsin at an enzyme-to-substrate ratio of 1:20. Digestion was carried out overnight at $37^{\circ} \mathrm{C}$. After digestion, the derivatization reaction was repeated to label peptide $\mathrm{N}$ termini. Samples were desalted using C18 ZipTips prior to nano liquid chromatographytandem mass spectrometry (LC-MS/MS) analysis. All histone digests were analyzed on an Orbitrap Velos mass spectrometer coupled to an EASY-nLC 1000 system (Thermo Fisher Scientific, Bremen, Germany) equipped with a Nanospray Flex ion source as it has been described elsewhere ${ }^{64}$. The flow rate was set to $300 \mathrm{~nL} / \mathrm{min}$. All four samples were analyzed in triplicate. A gradient consisting of solvent $\mathrm{A}$ $\left(97 \% \mathrm{H}_{2} \mathrm{O}_{\mathrm{dd}}, 3 \% \mathrm{ACN}, 0.1 \% \mathrm{FA}\right)$ and solvent $\mathrm{B}\left(97 \% \mathrm{ACN}, 3 \% \mathrm{H}_{2} \mathrm{O}_{\mathrm{dd}}, 0.1 \% \mathrm{FA}\right)$ running linearly from 2 to $28 \% \mathrm{~B}$ within $40 \mathrm{~min}$, followed by an increase to $42 \% \mathrm{~B}$ within 12 min was applied. For C18 column regeneration, the gradient was ramped up to $95 \%$ B within 5 min and kept at $95 \%$ B for 5 min. Data were acquired using data-dependent MS/MS mode as described in ref. ${ }^{62}$ with minor modifications. In brief, for the first $18 \mathrm{~min}$ each high-resolution precursor ion scan in the Orbitrap $(\mathrm{m} / \mathrm{z} 300-1250, R=60,000)$ was followed by high-resolution product ion scans (isolation window $2 \mathrm{Th}$ ) after higher-energy collisional dissociation at 35\% normalized collision energy (NE). The resolution was set to 7500 . The 8 most abundant signals with a charge state $\geq 2$ and a minimal intensity of 15,000 were selected for fragmentation, followed by dynamic exclusion for $30 \mathrm{~s}$. For the next $20 \mathrm{~min}$, MS1 data were acquired with the same settings, but an inclusion list was further used containing five ions, which represent isobaric and co-eluting histone peptides (H3 9-17aa 1 acetyl ( $m / z$ 528.30), H3 18-26aa 1 acetyl $(m / z$ 570.84), H4 4-17aa 1 acetyl $(\mathrm{m} / \mathrm{z} 768.95), \mathrm{H} 44-17$ aa 2 acetyls $(\mathrm{m} / \mathrm{z} 761.94), \mathrm{H} 44-17$ aa 3 acetyls $(\mathrm{m} / z$ 754.93)). Peptides were isolated and dissociated with the same settings as described above. Besides repeatedly triggering these five ions for MS2 over this time frame, a Top 3 method was additionally included to fragment other eluting peptides in this window. For the last $22 \mathrm{~min}$, the same Top 8 acquisition strategy was chosen as for the first $18 \mathrm{~min}$ of the LC-MS/MS run. All data were analyzed using EpiProfile 2.0 with standard settings, as described previously ${ }^{65}$. All RAW data are publicly available via Chorus (https://chorusproject.org/pages/index.html; ID 1497). 
Statistical analysis. Statistical analysis was performed using Prism software. Data represented as mean + s.d. or s.e.m., as indicated. Significant differences were calculated using Student's $t$-test where indicated. For laser micro-irradiation data, differences in the overall recruitment to damage sites was determined by a two-way analysis of variance (ANOVA; multiple conditions with multiple time points) and subsequently analyzed by Tukey's test to determine differences at individual time points. For all tests, $P$ values are as follows: NS non-significant $(>0.05)$; ${ }^{*}$ statistically significant $(<0.05) ;{ }^{* *}$ statistically significant $(<0.01) ;{ }^{* * *}$ statistically significant $(<0.001) ;{ }^{* * *}$ statistically significant $(<0.0001)$. Experiments were repeated a sufficient independent number of times to ensure reproducibility of results. See specific figure legends and Methods sections for details.

Reporting summary. Further information on experimental design is available in the Nature Research Reporting Summary linked to this article.

\section{Data availability}

The data sets generated and/or analyzed during the current study are available from the corresponding author on reasonable request. The raw data from the Mass Spectrometry analysis of histones are publicly available via Chorus (https:// chorusproject.org/pages/index.html; ID 1497).

Received: 7 March 2018 Accepted: 14 December 2018 Published online: 16 January 2019

\section{References}

1. Stanley, F. K., Moore, S. \& Goodarzi, A. A. CHD chromatin remodelling enzymes and the DNA damage response. Mutat. Res. 750, 31-44 (2013).

2. Marfella, C. G. \& Imbalzano, A. N. The Chd family of chromatin remodelers. Mutat. Res. 618, 30-40 (2007).

3. Luijsterburg, M. S. et al. PARP1 links CHD2-mediated chromatin expansion and H3.3 deposition to DNA repair by non-homologous end-joining. Mol. Cell 61, 547-562 (2016).

4. Chou, D. M. et al. A chromatin localization screen reveals poly (ADP ribose)regulated recruitment of the repressive polycomb and NuRD complexes to sites of DNA damage. Proc. Natl. Acad. Sci. USA 107, 18475-18480 (2010).

5. Larsen, D. H. et al. The chromatin-remodeling factor CHD4 coordinates signaling and repair after DNA damage. J. Cell. Biol. 190, 731-740 (2010).

6. Pan, M. R. et al. Chromodomain helicase DNA-binding protein 4 (CHD4) regulates homologous recombination DNA repair, and its deficiency sensitizes cells to poly(ADP-ribose) polymerase (PARP) inhibitor treatment. J. Biol. Chem. 287, 6764-6772 (2012).

7. Polo, S. E., Kaidi, A., Baskcomb, L., Galanty, Y. \& Jackson, S. P. Regulation of DNA-damage responses and cell-cycle progression by the chromatin remodelling factor CHD4. EMBO J 29, 3130-3139 (2010).

8. Smeenk, G. et al. The NuRD chromatin-remodeling complex regulates signaling and repair of DNA damage. J. Cell. Biol. 190, 741-749 (2010).

9. Goodarzi, A. A., Kurka, T. \& Jeggo, P. A. KAP-1 phosphorylation regulates CHD3 nucleosome remodeling during the DNA double-strand break response. Nat. Struct. Mol. Biol. 18, 831-839 (2011).

10. Klement, $\mathrm{K}$. et al. Opposing ISWI- and CHD-class chromatin remodeling activities orchestrate heterochromatic DNA repair. J. Cell. Biol. 207, 717-733 (2014).

11. Kari, V. et al. Loss of CHD1 causes DNA repair defects and enhances prostate cancer therapeutic responsiveness. EMBO Rep. 17, 1609-1623 (2016).

12. Luijsterburg, M. S. et al. A new non-catalytic role for ubiquitin ligase RNF8 in unfolding higher-order chromatin structure. EMBO J. 31, 2511-2527 (2012).

13. Shenoy, T. R. et al. CHD1 loss sensitizes prostate cancer to DNA damaging therapy by promoting error-prone double-strand break repair. Ann. Oncol. 28, 1495-1507 (2017).

14. Schuster, E. F. \& Stoger, R. CHD5 defines a new subfamily of chromodomainSWI2/SNF2-like helicases. Mamm. Genome 13, 117-119 (2002).

15. Thompson, P. M., Gotoh, T., Kok, M., White, P. S. \& Brodeur, G. M. CHD5, a new member of the chromodomain gene family, is preferentially expressed in the nervous system. Oncogene 22, 1002-1011 (2003).

16. Moshkin, Y. M. et al. Remodelers organize cellular chromatin by counteracting intrinsic histone-DNA sequence preferences in a class-specific manner. Mol. Cell. Biol. 32, 675-688 (2012).

17. Manning, B. J. \& Yusufzai, T. The ATP-dependent chromatin remodeling enzymes CHD6, CHD7, and CHD8 exhibit distinct nucleosome binding and remodeling activities. J. Biol. Chem. 292, 11927-11936 (2017).

18. de Dieuleveult, M. et al. Genome-wide nucleosome specificity and function of chromatin remodellers in ES cells. Nature 530, 113-116 (2016).
19. Lathrop, M. J. et al. Deletion of the Chd6 exon 12 affects motor coordination. Mamm. Genome 21, 130-142 (2010).

20. Hoch, N. C. et al. XRCC1 mutation is associated with PARP1 hyperactivation and cerebellar ataxia. Nature 541, 87-91 (2017).

21. McKinnon, P. J. \& Caldecott, K. W. DNA strand break repair and human genetic disease. Annu. Rev. Genom. Hum. Genet. 8, 37-55 (2007).

22. March, H. N. et al. Insertional mutagenesis identifies multiple networks of cooperating genes driving intestinal tumorigenesis. Nat. Genet. 43, 1202-1209 (2011).

23. Bhattacharyya, A., Chattopadhyay, R., Mitra, S. \& Crowe, S. E. Oxidative stress: an essential factor in the pathogenesis of gastrointestinal mucosal diseases. Physiol. Rev. 94, 329-354 (2014).

24. Cerda, C. et al. Oxidative stress and DNA damage in obesity-related tumorigenesis. Adv. Exp. Med. Biol. 824, 5-17 (2014)

25. Wang, H. P. et al. Identification of differentially transcribed genes in human lymphoblastoid cells irradiated with 0.5 Gy of gamma-ray and the involvement of low dose radiation inducible CHD6 gene in cell proliferation and radiosensitivity. Int. J. Radiat. Biol. 82, 181-190 (2006).

26. Tang, J. et al. Acetylation limits 53BP1 association with damaged chromatin to promote homologous recombination. Nat. Struct. Mol. Biol. 20, 317-325 (2013).

27. Fisher, A. E., Hochegger, H., Takeda, S. \& Caldecott, K. W. Poly(ADP-ribose) polymerase 1 accelerates single-strand break repair in concert with poly(ADPribose) glycohydrolase. Mol. Cell. Biol. 27, 5597-5605 (2007).

28. El-Khamisy, S. F., Masutani, M., Suzuki, H. \& Caldecott, K. W. A requirement for PARP-1 for the assembly or stability of XRCC1 nuclear foci at sites of oxidative DNA damage. Nucleic Acids Res. 31, 5526-5533 (2003).

29. Breslin, C. et al. The XRCC1 phosphate-binding pocket binds poly (ADPribose) and is required for XRCC1 function. Nucleic Acids Res. 43, 6934-6944 (2015).

30. Kaidi, A. \& Jackson, S. P. KAT5 tyrosine phosphorylation couples chromatin sensing to ATM signalling. Nature 498, 70-74 (2013).

31. Sun, Y. et al. Histone $\mathrm{H} 3$ methylation links DNA damage detection to activation of the tumour suppressor Tip60. Nat. Cell Biol. 11, 1376-1382 (2009).

32. Pleschke, J. M., Kleczkowska, H. E., Strohm, M. \& Althaus, F. R. Poly(ADP ribose) binds to specific domains in DNA damage checkpoint proteins. J. Biol. Chem. 275, 40974-40980 (2000).

33. Nioi, P., Nguyen, T., Sherratt, P. J. \& Pickett, C. B. The carboxy-terminal Neh3 domain of Nrf2 is required for transcriptional activation. Mol. Cell. Biol. 25, 10895-10906 (2005)

34. Gorrini, C., Harris, I. S. \& Mak, T. W. Modulation of oxidative stress as an anticancer strategy. Nat. Rev. Drug. Discov. 12, 931-947 (2013).

35. Goodarzi, A. A. \& Jeggo, P. A. Irradiation induced foci (IRIF) as a biomarker for radiosensitivity. Mutat. Res. 736, 39-47 (2012)

36. Nagel, Z. D., Chaim, I. A. \& Samson, L. D. Inter-individual variation in DNA repair capacity: a need for multi-pathway functional assays to promote translational DNA repair research. DNA Repair (Amst.). 19, 199-213 (2014).

37. Nagel, Z. D. et al. Multiplexed DNA repair assays for multiple lesions and multiple doses via transcription inhibition and transcriptional mutagenesis. Proc. Natl. Acad. Sci. USA 111, E1823-E1832 (2014).

38. Chaim, I. A. et al. In vivo measurements of interindividual differences in DNA glycosylases and APE1 activities. Proc. Natl. Acad. Sci. USA 114, E10379-E10388 (2017).

39. Noon, A. T. et al. 53BP1-dependent robust localized KAP-1 phosphorylation is essential for heterochromatic DNA double-strand break repair. Nat. Cell Biol. 12, 177-184 (2010).

40. Krempler, A., Deckbar, D., Jeggo, P. A. \& Lobrich, M. An imperfect G(2)/M checkpoint contributes to chromosome instability following irradiation of $\mathrm{S}$ and G(2) phase cells. Cell Cycle 6, 1682-1686 (2007).

41. Brunton, H. et al. Analysis of human syndromes with disordered chromatin reveals the impact of heterochromatin on the efficacy of ATM-dependent G2/ M checkpoint arrest. Mol. Cell. Biol. 31, 4022-4035 (2011).

42. Murga, M. et al. Global chromatin compaction limits the strength of the DNA damage response. J. Cell. Biol. 178, 1101-1108 (2007).

43. Strickfaden, H. et al. Poly(ADP-ribosyl)ation-dependent transient chromatin decondensation and histone displacement following laser microirradiation. $J$. Biol. Chem. 291, 1789-1802 (2016).

44. Goodarzi, A. A. et al. ATM signaling facilitates repair of DNA doublestrand breaks associated with heterochromatin. Mol. Cell 31, 167-177 (2008).

45. Chen, Z. H. et al. PTEN interacts with histone $\mathrm{H} 1$ and controls chromatin condensation. Cell Rep. 8, 2003-2014 (2014).

46. Berger, N. D., Stanley, F. K. T., Moore, S. \& Goodarzi, A. A. ATM-dependent pathways of chromatin remodelling and oxidative DNA damage responses. Philos. Trans. R. Soc. Lond. B. Biol. Sci. 372, pii: 20160283 (2017). 
47. Fertey, J. et al. Interaction of the papillomavirus E8--E2C protein with the cellular CHD6 protein contributes to transcriptional repression. J. Virol. 84 9505-9515 (2010).

48. Guo, Z., Kozlov, S., Lavin, M. F., Person, M. D. \& Paull, T. T. ATM activation by oxidative stress. Science 330, 517-521 (2010).

49. Khoronenkova, S. V. \& Dianov, G. L. ATM prevents DSB formation by coordinating SSB repair and cell cycle progression. Proc. Natl. Acad. Sci. USA 112, 3997-4002 (2015)

50. Sancho, A. et al. CHD6 regulates the topological arrangement of the CFTR locus. Hum. Mol. Genet. 24, 2724-2732 (2015).

51. Andrabi, S. A. et al. Poly(ADP-ribose) polymerase-dependent energy depletion occurs through inhibition of glycolysis. Proc. Natl. Acad. Sci. USA 111, 10209-10214 (2014).

52. Silva, A. P. et al. The N-terminal region of chromodomain helicase DNAbinding protein 4 (CHD4) is essential for activity and contains a high mobility group (HMG) box-like-domain that can bind poly(ADP-ribose). J. Biol. Chem. 291, 924-938 (2016).

53. Jaramillo, M. C. \& Zhang, D. D. The emerging role of the Nrf2-Keap1 signaling pathway in cancer. Genes Dev. 27, 2179-2191 (2013).

54. Janicki, S. M. et al. From silencing to gene expression: real-time analysis in single cells. Cell 116, 683-698 (2004).

55. Lan, L. et al. Novel method for site-specific induction of oxidative DNA damage reveals differences in recruitment of repair proteins to heterochromatin and euchromatin. Nucleic Acids Res. 42, 2330-2345 (2014).

56. Mortusewicz, O., Ame, J. C., Schreiber, V. \& Leonhardt, H. Feedbackregulated poly(ADP-ribosyl)ation by PARP-1 is required for rapid response to DNA damage in living cells. Nucleic Acids Res. 35, 7665-7675 (2007).

57. Cinti, A. et al. Simultaneous overexpression of functional human HO-1, E5NT and ENTPD1 protects murine fibroblasts against TNF-alpha-induced injury in vitro. PLoS One 10, e0141933 (2015).

58. Kremers, G. J., Hazelwood, K. L., Murphy, C. S., Davidson, M. W. \& Piston, D. W. Photoconversion in orange and red fluorescent proteins. Nat. Methods 6 , 355-358 (2009).

59. Shalem, O. et al. Genome-scale CRISPR-Cas9 knockout screening in human cells. Science 343, 84-87 (2014).

60. Kiziltepe, T. et al. Delineation of the chemical pathways underlying nitric oxide-induced homologous recombination in mammalian cells. Chem. Biol. 12, 357-369 (2005).

61. Shechter, D., Dormann, H. L., Allis, C. D. \& Hake, S. B. Extraction, purification and analysis of histones. Nat. Protoc. 2, 1445-1457 (2007).

62. Karch, K. R., Sidoli, S. \& Garcia, B. A. Identification and quantification of histone PTMs using high-resolution mass spectrometry. Methods Enzymol. 574, 3-29 (2016).

63. Sidoli, S., Bhanu, N. V., Karch, K. R., Wang, X. \& Garcia, B. A. Complete workflow for analysis of histone post-translational modifications using bottom-up mass spectrometry: from histone extraction to data analysis. J. Vis. Exp. 111, e54112 (2016). https://doi.org/10.3791/54112. https://www.ncbi.nlm. nih.gov/pubmed/27286567

64. Schräder, C. U., Ziemianowicz, D. S., Merx, K. \& Schriemer, D. C. Simultaneous proteoform analysis of histones $\mathrm{H} 3$ and $\mathrm{H} 4$ with a simplified middle-down proteomics method. Anal. Chem. 90, 3083-3090 (2018).

65. Yuan, Z. F. et al. EpiProfile 2.0: a computational platform for processing epiproteomics mass spectrometry data. J. Proteome Res. 17, 2533-2541 (2018).

\section{Acknowledgements}

We thank Brielle Cram, Connor Pettem and Luc Boutin for preliminary work; Dr. Anne Vaahtokari and the Charbonneau Institute Microscopy Facility for imaging assistance; Sophie Briggs and the lab of Dr. Jennifer Cobb for qPCR advice; Justin Simms for CRISPR advice; Yaping Yu for gene sequence analysis; Keith Caldecott for comet assay advice and Roger Greenberg for providing the FOK1-LacR cells. MSL is supported by a VENI fellowship (ALW-863.11.007) and VIDI fellowship (ALW-016.161.320) from the Netherlands Scientific Organization (NWO). HvA is supported by an ERC Consolidator grant from the European Research Council. CGP and the ZDN lab is supported by SBDR P01 CA092584. CUS and the DCS lab are supported by an NSERC RGPIN-2017-04879 grant. SM was supported by an Achievers in Medical Sciences award. AAG is the Canada Research Chair for Radiation Exposure Disease and this work was undertaken, in part, thanks to funding from the Canada Research Chairs program. The AAG laboratory is supported by the Canadian Institutes of Health Research.

\section{Author contributions}

In the A.A.G. lab, A.A.G. and S.M. designed the study and contributed to all figures, N.D. B. (co-supervised by A.A.G. and J.A.C.) provided data in Figs. 1, 4, 5 and F.K.T.S. provided data in Fig. 1 and Supplementary Fig. 1. M.S.L. and H.v.A. provided data in Fig. 2. C.G.P. with Z.D.N. and C.U.S. with D.C.S. provided data in Fig. 5. S.F. generated CHD6 constructs. All authors contributed to manuscript preparation.

\section{Additional information}

Supplementary Information accompanies this paper at https://doi.org/10.1038/s41467018-08111-y.

Competing interests: The authors declare no competing interests.

Reprints and permission information is available online at http://npg.nature.com/ reprintsandpermissions/

Journal peer review information: Nature Communications thanks the anonymous reviewers for their contribution to the peer review of this work. Peer reviewer reports are available.

Publisher's note: Springer Nature remains neutral with regard to jurisdictional claims in published maps and institutional affiliations.

Open Access This article is licensed under a Creative Commons Attribution 4.0 International License, which permits use, sharing, adaptation, distribution and reproduction in any medium or format, as long as you give appropriate credit to the original author(s) and the source, provide a link to the Creative Commons license, and indicate if changes were made. The images or other third party material in this article are included in the article's Creative Commons license, unless indicated otherwise in a credit line to the material. If material is not included in the article's Creative Commons license and your intended use is not permitted by statutory regulation or exceeds the permitted use, you will need to obtain permission directly from the copyright holder. To view a copy of this license, visit http://creativecommons.org/ licenses/by/4.0\%.

(C) The Author(s) 2019 